\title{
The experimental validation of a numerical model for the prediction of railway induced vibrations
}

\author{
G. Lombaert*, G. Degrande, J. Kogut, S. François \\ Department of Civil Engineering, K.U.Leuven, Kasteelpark Arenberg 40, B-3001 Leuven, Belgium
}

Received 21 June 2004; received in revised form 23 March 2006; accepted 30 March 2006

Available online 19 June 2006

\begin{abstract}
This paper presents the experimental validation of a numerical model for the prediction of train induced vibrations. The model fully accounts for the dynamic interaction between the train, the track and the soil. The track geometry is assumed to be invariant with respect to the longitudinal direction, which allows for an efficient solution of the dynamic track-soil interaction problem in the frequency-wavenumber domain. The model is validated by means of several experiments that have been performed at the occasion of the homologation tests of the new HST track on the line L2 between Brussels and Köln. A first set of experiments is used to determine the dynamic soil and track characteristics. In a second set of experiments, the soil transfer functions, the track-soil transfer functions and the track and free field vibrations during the passage of a Thalys high speed train have been measured. These results are used for a step-wise validation of the numerical model that is based on the identified model parameters and allows to study the propagation of errors in the prediction model. (C) 2006 Elsevier Ltd. All rights reserved.
\end{abstract}

\section{Introduction}

The development of the high speed train (HST) network in Europe, the USA and Asia has increased the interest for ground-borne vibrations in the built environment. Ground-borne railway induced vibrations are generated by a large number of excitation mechanisms. For HST tracks on soft soils, the train speed can be close to or even larger than the critical phase velocity of the coupled track-soil system. In this case, the quasistatic contribution of the load is important for both the track and the free field response. High vibration levels and track displacements are obtained, affecting track stability and safety [1]. For the X2000 train, track deformations upto $10 \mathrm{~mm}$ have been reported at a site in Ledsgård along the West Coast Line in Sweden [2]. Kaynia et al. [3] and Madshus and Kaynia [4] have studied this problem by means of a model where the track is represented by beam elements and the track impedance is coupled to a soil impedance that is calculated by means of the disc Green's functions for a horizontally layered half-space. The same problem has been studied by Ekevid and Wiberg [5] who combine the finite element method and the scaled boundary element method. Andersen and Nielsen [6] apply a boundary element method for the steady-state response of an elastic medium in a moving frame of reference.

*Corresponding author. Fax: +3216321988 .

E-mail address: geert.lombaert@bwk.kuleuven.be (G. Lombaert). 
In the case where the train speed is well below the wave velocities in the soil, however, the quasi-static contribution to the free field response is small compared to the contribution of the dynamic axle loads. The dynamic axle loads are generated by parametric excitation due to the discrete supports of the rails, transient excitation due to rail joints and wheelflats and the excitation due to wheel and rail roughness and track unevenness [7]. The interaction between the train and the track cannot be disregarded when calculating the dynamic axle loads, as the resonance of the mass of the wheels or the entire vehicle against the stiffness of the substructure is important [8].

The development of three-dimensional numerical models that account for the dynamic interaction between the train, the track and the soil has recently received considerable attention. Sheng et al. $[9,10]$ have modelled the track-soil interaction by means of a model with an infinite layered beam on top of a layered half-space and have coupled a train model to this track model [11,12]. Auersch [13] has coupled a finite element model for a finite part of the track to a boundary element model for the soil. This model is used for the calculation of the track compliance in the solution of the vehicle-track interaction problem. Metrikine et al. [14] have studied the stability of a moving train bogie, modelled as a two degree of freedom system, which is coupled to a beam of infinite length for the track and a homogeneous half-space model for the soil, following an approach proposed by Metrikine and Popp [15].

The aim of the present paper is twofold. The first objective is to present a numerical model for the prediction of railway induced vibrations [16,17]. This model is based on a prediction model for road traffic induced vibrations $[18,19]$, that has been validated by means of in situ experiments $[20,21]$. The model has been elaborated in order to account for the dynamic interaction between the vehicle and the track by means of a compliance formulation in the frame of reference that moves with the vehicle [22]. The railway track is modelled as a longitudinally invariant system, and is assumed to be located at the surface of a horizontally layered elastic half-space. The translational invariance of the problem geometry enables an efficient solution in the frequency-wavenumber domain.

The second objective of the paper is to validate this numerical model by means of several experiments that have been performed at the occasion of the homologation tests of the line L2 of the HST between Brussels and Köln. These homologation tests have been performed with an IC train at a speed between 155.9 and $225.3 \mathrm{~km} / \mathrm{h}$ and a Thalys HST at a speed between 218.1 and $326.1 \mathrm{~km} / \mathrm{h}$.

A first set of experiments is used to identify the model parameters. The dynamic soil characteristics are determined by means of seismic cone penetration tests (SCPT) and spectral analysis of surface waves (SASW) tests. A rail receptance test is used for the determination of the dynamic track characteristics.

A second set of experiments is used to validate the results of the numerical model, using the identified model parameters. The validation is performed in three steps with an increasing complexity and an increasing number of input parameters:

(1) In the SASW tests $[23,24]$, an impact force on a steel foundation is used to generate vibrations at the soil's surface. The phase of the cross-power spectrum of the response at different distances is subsequently used to identify the experimental dispersion curve of the first surface wave. Next, the solution of an optimization problem allows to determine the shear wave velocity profile of the site. During these tests, the impact force has also been measured [25], which allows to determine the experimental transfer function between the steel foundation and the free field. This transfer function is used to validate the results of the numerical model.

(2) The measured transfer or mobility functions between the track and the free field [26] are compared to the computed transfer functions, which depend on both the dynamic soil and track characteristics.

(3) The in situ vibration measurements during the passage of a Thalys HST at two speeds of 218 and $294 \mathrm{~km} / \mathrm{h}$ $[27,28]$ are used to validate the numerical prediction of the sleeper response and the free field vibrations during the passage of a train on an uneven track, accounting for dynamic train-track-soil interaction.

The experimental validation presented in the following is complementary to results presented by Sheng et al. [11] and Auersch [13], as more emphasis goes here to the determination of the model parameters and the validation of intermediate results. 


\section{The numerical prediction model}

\subsection{The train-track interaction problem}

The dynamic axle loads are determined by the dynamic interaction between the train, the track and the soil. The dynamic train-track interaction problem is solved by means of a compliance formulation in the frame of reference that moves with the vehicle [22]. In the following, the contact between the axles and the rails is approximated as a point contact. When a perfect contact is assumed between the vehicle and the railway track, the displacement vector $\hat{\mathbf{u}}_{c}$ that contains the vehicle displacements at the vehicle-track contact points is equal to the sum of the rail displacement $\hat{\mathbf{u}}_{r}$ and the rail unevenness $\hat{\mathbf{u}}_{w / r}$ :

$$
\hat{\mathbf{u}}_{c}=\hat{\mathbf{u}}_{r}+\hat{\mathbf{u}}_{w / r}
$$

where both the rail displacements $\hat{\mathbf{u}}_{r}$ and the rail unevenness $\hat{\mathbf{u}}_{w / r}$ are evaluated at a fixed position in the moving frame of reference.

The vehicle is usually modelled as a multi-degree of freedom system, where the vehicle's axles and body are considered as rigid parts and the vehicle's suspension is represented by spring and damper elements. The vehicle's equations of motion can be written in the following general form, making a distinction between the displacements $\hat{\mathbf{u}}_{b}$ of the body, $\hat{\mathbf{u}}_{a}$ of the axles and $\hat{\mathbf{u}}_{c}$ at the vehicle-track contact points:

$$
\left[\begin{array}{ccc}
\mathbf{S}_{b b} & \mathbf{S}_{b a} & 0 \\
\mathbf{S}_{a b} & \mathbf{S}_{a a}+\mathbf{S}_{a a}^{H} & -\mathbf{S}_{a a}^{H} \\
0 & -\mathbf{S}_{a a}^{H} & \mathbf{S}_{a a}^{H}
\end{array}\right]\left\{\begin{array}{c}
\hat{\mathbf{u}}_{b} \\
\hat{\mathbf{u}}_{a} \\
\hat{\mathbf{u}}_{c}
\end{array}\right\}=\left\{\begin{array}{c}
\mathbf{0} \\
\mathbf{0} \\
-\hat{\mathbf{g}}
\end{array}\right\},
$$

where $\mathbf{S}$ represents a dynamic stiffness matrix. $\mathbf{S}_{a a}^{H}$ is the dynamic stiffness matrix that corresponds to the Hertzian springs between the wheels and the rails. The solution of these equations of motion allows for the computation of the vehicle's compliance matrix $\hat{\mathbf{C}}^{v}$ that relates the displacements $\hat{\mathbf{u}}_{c}$ to the vehicle-track interaction forces $\hat{\mathbf{g}}$ :

$$
\hat{\mathbf{u}}_{c}=-\hat{\mathbf{C}}^{v} \hat{\mathbf{g}} .
$$

Each element $\hat{C}_{k l}^{v}$ of the vehicle's compliance matrix represents the displacements at the contact point $k$ due to a unit impulse load at the contact point $l$.

In the following, it will be shown how, in the case of a longitudinally invariant track, the track displacements $\hat{\mathbf{u}}_{r}$ at the contact points between the vehicle and the track can be calculated in a similar way:

$$
\hat{\mathbf{u}}_{r}=\hat{\mathbf{C}}^{t} \hat{\mathbf{g}}
$$

Each element $\hat{C}_{k l}^{t}$ of the track compliance matrix $\hat{\mathbf{C}}^{t}$ represents the track displacements at the time-dependent position of the $k$ th axle due to an impulsive load at the time-dependent position of the $l$ th axle. The calculation is based on the solution of the moving load problem in a moving frame of reference.

The introduction of Eqs. (3) and (4) in Eq. (1) yields the following system of equations:

$$
\left[\hat{\mathbf{C}}^{v}+\hat{\mathbf{C}}^{t}\right] \hat{\mathbf{g}}=-\hat{\mathbf{u}}_{w / r}
$$

This equation allows to compute, in the frequency domain, the vehicle-track interaction forces $\hat{\mathbf{g}}$ from the track unevenness $\hat{\mathbf{u}}_{w / r}$ as applied to the train's axles.

The frequency content $\hat{\mathbf{u}}_{w / r}(\omega)$ of the track unevenness is calculated from the wavenumber domain representation $\tilde{u}_{w / r}\left(k_{y}\right)$ of the unevenness $u_{w / r}(y)$ :

$$
\hat{\mathbf{u}}_{w / r}(\omega)=\frac{1}{v} \tilde{u}_{w / r}\left(-\frac{\omega}{v}\right) \exp \left(\mathrm{i} \omega \frac{\mathbf{y}_{a}}{v}\right)
$$

where the vector $\mathbf{y}_{a}$ contains the initial positions $y_{k}$ of all axles $k$. The vector $\exp \left(\mathrm{i} \omega \mathbf{y}_{a} / v\right)$ includes the phase difference between the excitation at different axles. 


\subsection{The track-soil interaction problem}

In this subsection, the equations of motion of the coupled track-soil system are solved for a vertical impulse load at a fixed track position $\left\{x_{S}, 0, z_{S}\right\}^{\mathrm{T}}$. The track is assumed to be located at the surface of a horizontally layered half-space, with a geometry that is invariant in the longitudinal direction $\mathbf{e}_{y}$. The solution procedure can be applied to continuously supported tracks (Fig. 1a), as well as to discretely supported tracks (Fig. 1b), provided equivalent characteristics of the discrete track are calculated. Knothe and Grassie [29] have investigated the track receptance of a discretely supported track and show how the rail receptance at a sleeper and in between sleepers has a similar behaviour upto about $500 \mathrm{~Hz}$. Knothe and $\mathrm{Wu}$ [30] have compared the track receptance for a discretely supported track and a continuously supported track and found similar results upto $600 \mathrm{~Hz}$. Equivalent continuous track models therefore provide a reliable prediction of the track receptance, but do not account for parametric excitation as the small spatial variation of the support stiffness of the discretely supported track is disregarded.

In the following, the numerical model will be validated by means of experiments that have been performed at a site in Lincent, along the line L2 of the new HST track between Brussels and Köln. The HST track at this site is a classical ballasted track with a discrete support of the rails by sleepers. An equivalent continuous model, as shown in Fig. 2, will be applied. Examples of models for continuous slab tracks can be found elsewhere [31].

The rails are modelled as Euler-Bernoulli beams with a bending stiffness $E_{r} I_{r}$ and a mass $\rho_{r} A_{r}$ per unit length. The rail displacements are denoted as $u_{r 1}(y, t)$ and $u_{r 2}(y, t)$. The positions of the rail are determined by $l_{1}$ and $l_{2}$.

The rail pads are modelled as continuous spring-damper connections. The rail pad stiffness $k_{\mathrm{rp}}$ and damping coefficient $c_{\mathrm{rp}}$ of a single rail pad are used to calculate an equivalent stiffness $\bar{k}_{\mathrm{rp}}=k_{\mathrm{rp}} / d$ and damping coefficient $\bar{c}_{\mathrm{rp}}=c_{\mathrm{rp}} / d$ in the continuous model, where $d$ is the sleeper distance.

The sleepers are assumed to be rigid in the plane of the track cross section, so that the vertical sleeper displacements along the track are determined by the vertical displacement $u_{\mathrm{sl}}(y, t)$ at the centre of gravity of the sleeper and the rotation $\beta_{\mathrm{sl}}(y, t)$ about this centre. The sleepers are assumed not to contribute to the
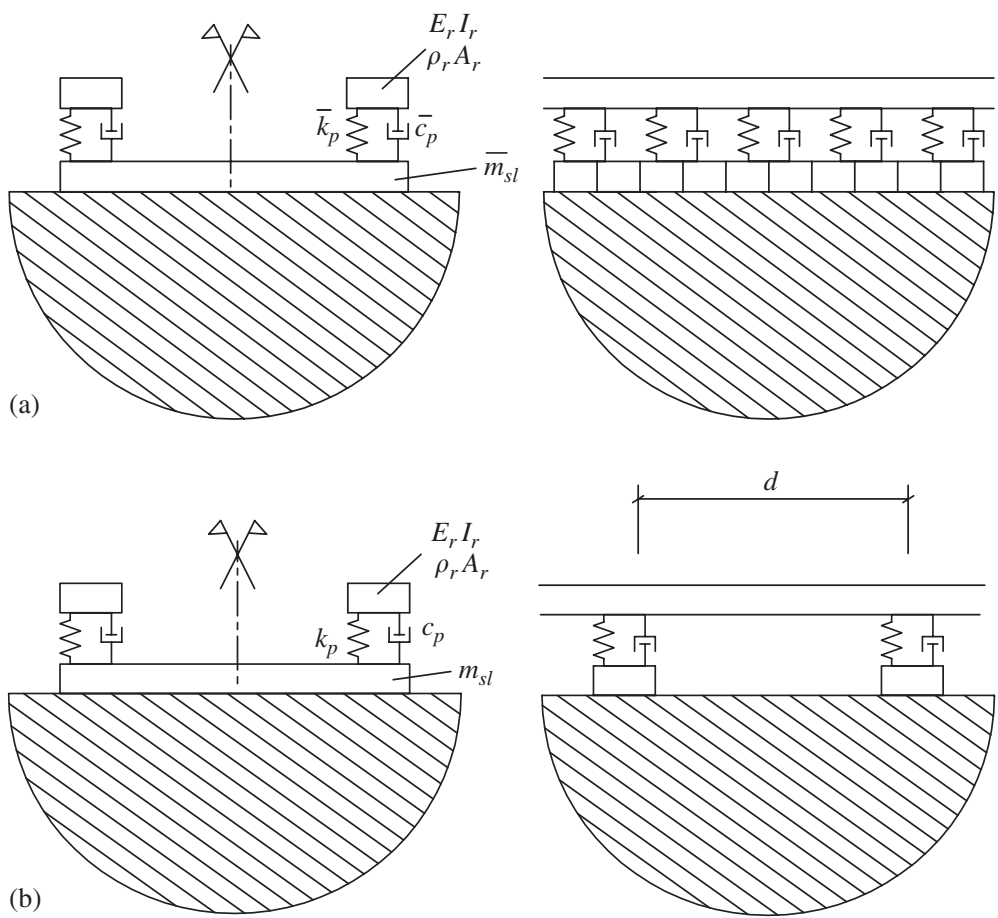

Fig. 1. Alternative models of a ballasted track. 


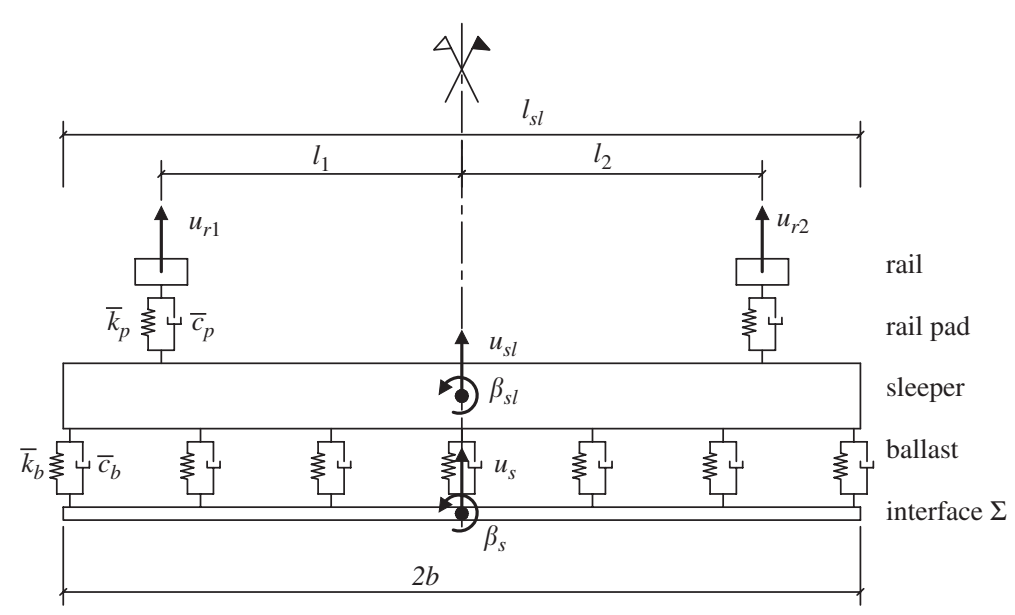

Fig. 2. Cross section of a ballasted track model.

longitudinal stiffness of the track, so that they can be modelled as a uniformly distributed mass along the track. The sleeper mass $m_{\mathrm{sl}}$ is used to calculate a uniformly distributed mass $\bar{m}_{\mathrm{sl}}=m_{\mathrm{sl}} / d$ per unit length. The width $2 b$ of the track-soil interface is taken equal to the sleeper length $l_{\mathrm{s}}$.

If the ballast bed is assumed to act as a set of distributed, independent linear springs and dampers, each sleeper is only supported by that part of the ballast that is in contact with the sleeper. For reasons of stability, the sleeper is usually only supported under the rails, so that the vertical spring stiffness $k_{b}$ per sleeper $[\mathrm{N} / \mathrm{m}]$ is calculated from the effective support length $e_{\mathrm{sl}}$ per rail, the sleeper width $b_{\mathrm{sl}}$ and the ballast stiffness $K_{b}$ [N/ $/ \mathrm{m}^{3}$ ] as $2 e_{\mathrm{sl}} b_{\mathrm{sl}} K_{b}$. The smeared ballast stiffness $\bar{k}_{b}\left[\mathrm{~N} / \mathrm{m}^{2}\right]$ is equal to $k_{b} / d$. When viscous damping in the ballast bed is accounted for, the ballast impedance equals $\bar{k}_{b}+\mathrm{i} \omega \bar{c}_{b}$. In a similar way, the discrete support of the sleepers and the effective width determine the part of the ballast mass that is coupled to the sleepers and to the soil.

The track-soil interface is assumed to be rigid in the plane of the track cross section. The vertical displacements $u_{s z}(x, y, t)$ at the track-soil interface $\Sigma$ are therefore determined by the vertical displacement $u_{s}(y, t)$ at the centre of the track-soil interface and the rotation $\beta_{s}(y, t)$ about this centre:

$$
u_{s z}(x, y, t)=u_{s}(y, t)+\beta_{s}(y, t) x=\phi_{t}(x) \alpha(y, t) \quad \text { on } \quad \Sigma,
$$

where $\phi_{t}(x)$ is the vector $\{1, x\}$ that collects the displacement modes of the cross section, while the vector $\boldsymbol{\alpha}(y, t)$ collects the displacement $u_{s}(y, t)$ and the rotation $\beta_{s}(y, t)$, which can be interpreted as generalized degrees of freedom.

The invariance of the geometry with respect to the longitudinal coordinate $y$ allows to perform a Fourier transformation of the coordinate $y$ to the wavenumber $k_{y}$. This results in a solution procedure in the frequency-wavenumber domain, where the equations of motion of the coupled track-soil system can be written in the following general form:

$$
\left[\tilde{\mathbf{K}}_{\mathrm{tr}}+\tilde{\mathbf{K}}_{s}\right] \tilde{\mathbf{u}}_{\mathrm{tr}}=\tilde{\mathbf{f}}_{\mathrm{tr}},
$$

where $\tilde{\mathbf{K}}_{\text {tr }}$ and $\tilde{\mathbf{K}}_{s}$ represent the track and the soil impedance matrices, respectively, while $\tilde{\mathbf{u}}_{\mathrm{tr}}$ is the track displacement vector and $\tilde{\mathbf{f}}_{\mathrm{tr}}$ is the force vector applied to the track. A tilde above a variable denotes its representation in the frequency-wavenumber domain, so that the arguments $k_{y}$ and $\omega$ are omitted. The solution procedure has been originally proposed by Aubry et al. [32] and Clouteau et al. [22] to study the interaction of an infinite beam with a horizontally layered elastic half-space in the frequency-wavenumber domain.

The track displacement vector $\tilde{\mathbf{u}}_{\mathrm{tr}}$ collects the track displacements and the generalized degrees of freedom $\tilde{\boldsymbol{\alpha}}$ of the track-soil interface $\Sigma$. In the present case of a ballast track, the vector $\tilde{\mathbf{u}}_{\mathrm{tr}}$ equals $\left\{\tilde{u}_{r 1}, \tilde{u}_{r 2}, \tilde{u}_{\mathrm{sl}}, \tilde{\beta}_{\mathrm{sl}}, \tilde{u}_{s}, \tilde{\beta}_{s}\right\}^{\mathrm{T}}$. The track force vector $\tilde{\mathbf{f}}_{\text {tr }}$ contains the forces applied at both rails and is equal to $\left\{\tilde{f}_{r 1}, \tilde{f}_{r 2}, 0,0,0,0\right\}^{\mathrm{T}}$. 
The track impedance matrix $\tilde{\mathbf{K}}_{\mathrm{tr}}$ is further detailed as

$$
\begin{aligned}
& \tilde{\mathbf{K}}_{\mathrm{tr}} \\
& =\left[\begin{array}{ccc}
\tilde{K}_{r}+\tilde{K}_{\mathrm{rp}} & 0 & -\tilde{K}_{\mathrm{rp}} \\
0 & \tilde{K}_{r}+\tilde{K}_{\mathrm{rp}} & -\tilde{K}_{\mathrm{rp}} \\
-\tilde{K}_{\mathrm{rp}} & -\tilde{K}_{\mathrm{rp}} & 2 \tilde{K}_{\mathrm{rp}}+\tilde{K}_{\mathrm{sl}, b}+\tilde{K}_{b}-\frac{\bar{m}_{b}}{3} \omega^{2} \cdots \\
-\tilde{K}_{\mathrm{rp}} l_{1} & -\tilde{K}_{\mathrm{rp}} l_{2} & \tilde{K}_{\mathrm{rp}}\left(l_{1}+l_{2}\right) \\
0 & 0 & -\tilde{K}_{b}-\frac{\bar{m}_{b}}{6} \omega^{2} \\
0 & 0 & 0
\end{array}\right. \\
& \begin{array}{lll}
-\tilde{K}_{\mathrm{rp}} l_{1} & 0 & 0 \\
-\tilde{K}_{\mathrm{rp}} l_{2} & 0 & 0
\end{array} \\
& \ldots \quad \tilde{K}_{\mathrm{rp}}\left(l_{1}+l_{2}\right) \quad-\tilde{K}_{b}-\frac{\bar{m}_{b}}{6} \omega^{2} \quad 0 \\
& \tilde{K}_{\mathrm{s}, t}+\tilde{K}_{\mathrm{rp}}\left(l_{1}^{2}+l_{2}^{2}\right)+\frac{b^{2}}{3}\left(\tilde{K}_{b}-\frac{\bar{m}_{b}}{3} \omega^{2}\right) \quad 0 \quad-\frac{b^{2}}{3}\left(\tilde{K}_{b}+\frac{\bar{m}_{b}}{6} \omega^{2}\right), \\
& 0 \\
& \tilde{K}_{b}-\frac{\bar{m}_{b}}{3} \omega^{2} \quad 0 \\
& \left.-\frac{b^{2}}{3}\left(\tilde{K}_{b}+\frac{\bar{m}_{b}}{6} \omega^{2}\right) \quad 0 \quad \frac{b^{2}}{3}\left(\tilde{K}_{b}-\frac{\bar{m}_{b}}{3} \omega^{2}\right)\right]
\end{aligned}
$$

where $\tilde{K}_{r}$ denotes the rail impedance $E_{r} I_{r} k_{y}^{4}-\rho_{r} A_{r} \omega^{2}$ in the frequency-wavenumber domain and $\tilde{K}_{\mathrm{rp}}$ is the dynamic stiffness $\bar{k}_{\text {rp }}+\mathrm{i} \omega \bar{c}_{\text {rp }}$ of the rail pads. The sleeper's translational inertia $\tilde{K}_{\mathrm{sl}, b}$ and rotational inertia $\tilde{K}_{\mathrm{sl}, t}$ are calculated from the mass per unit length $\bar{m}_{\mathrm{sl}}$ as $-\bar{m}_{\mathrm{sl}} \omega^{2}$ and $-\left(b^{2} / 3\right) \bar{m}_{\mathrm{sl}} \omega^{2}$, respectively. The dynamic stiffness $\tilde{K}_{b}$ of the ballast in the vertical direction is equal to $\bar{k}_{b}+\mathrm{i} \omega \bar{c}_{b}$. The rotational impedance equals $\left(b^{2} / 3\right) \tilde{K}_{b}$, assuming a uniform support of the ballast along the width $2 b$ of the interface.

The weak formulation of the vertical equilibrium at the track-soil interface $\Sigma$ allows to calculate the soil impedance matrix $\tilde{\mathbf{K}}_{s}$ :

$$
\tilde{K}_{s i j}\left(k_{y}, \omega\right)=\int_{\Sigma} \phi_{t i} \tilde{t}_{s z}\left(\mathbf{u}_{\mathrm{sc}}\left(\phi_{t j}\right)\right) \mathrm{d} \Gamma
$$

where $\mathbf{u}_{\mathrm{sc}}\left(\phi_{t j}\right)$ is the wavefield in the soil due to an imposed displacement $\phi_{t j}$ at the track-soil interface $\Sigma$ in the frequency-wavenumber domain. $\tilde{t}_{s z}\left(\mathbf{u}_{\mathrm{sc}}\left(\phi_{t j}\right)\right)$ is the vertical component of the soil tractions $\tilde{\mathbf{t}}_{s}=\tilde{\boldsymbol{\sigma}}_{s} \mathbf{n}$ on a boundary with a unit outward normal $\mathbf{n}$ due to this scattered wavefield $\mathbf{u}_{\mathrm{sc}}\left(\phi_{t j}\right)$. In the present case, the soil impedance matrix is equal to

$$
\tilde{\mathbf{K}}_{s}=\left[\begin{array}{cccccc}
0 & 0 & 0 & 0 & 0 & 0 \\
0 & 0 & 0 & 0 & 0 & 0 \\
0 & 0 & 0 & 0 & 0 & 0 \\
0 & 0 & 0 & 0 & 0 & 0 \\
0 & 0 & 0 & 0 & \tilde{K}_{s 11} & 0 \\
0 & 0 & 0 & 0 & 0 & \tilde{K}_{s 22}
\end{array}\right]
$$


A boundary element method is used to calculate the soil tractions $\tilde{t}_{s z}\left(\mathbf{u}_{\mathrm{sc}}\left(\phi_{t j}\right)\right)$ at the track-soil interface, assuming that the track is located at the soil's surface $[18,32]$. The boundary element formulation is based on the boundary integral equations in the frequency-wavenumber domain, using the Green's functions of a horizontally layered soil [33-35]. Each layer in the half-space model is characterized by its thickness $d$, the dynamic soil characteristics $E$ and $v$ or the longitudinal and transversal wave velocities $C_{p}$ and $C_{s}$, the material density $\rho$ and a material damping ratio $\beta_{p}$ and $\beta_{s}$ in volumetric and deviatoric deformation, respectively.

The solution of the track-soil interaction equation (8) provides the soil displacements $\left\{\tilde{u}_{s}, \tilde{\beta}_{s}\right\}^{\mathrm{T}}$ at the track-soil interface $\Sigma$, which allow for the computation of the soil tractions $\tilde{t}_{s z}\left(x, k_{y}, z=0, \omega\right)$ at this interface:

$$
\tilde{t}_{s z}\left(x, k_{y}, z=0, \omega\right)=\tilde{\mathbf{t}}_{s z}\left(\mathbf{u}_{\mathrm{sc}}\left(\boldsymbol{\phi}_{t}\right)\right) \tilde{\boldsymbol{\alpha}},
$$

where $\tilde{\mathbf{t}}_{s z}\left(\mathbf{u}_{\mathrm{sc}}\left(\boldsymbol{\phi}_{t}\right)\right)$ collects the vertical component of the soil tractions due to the scattered wavefields in the soil.

The dynamic reciprocity theorem is used for the calculation of the track-soil transfer function $\tilde{h}_{z i}\left(x, k_{y}, z, \omega\right)$ :

$$
\tilde{h}_{z i}\left(x, k_{y}, z, \omega\right)=\int_{\Sigma} \tilde{u}_{z i}^{G}\left(x-x^{\prime}, k_{y}, z, \omega\right) \tilde{t}_{s z}\left(x^{\prime}, k_{y}, z^{\prime}=0, \omega\right) \mathrm{d} \Gamma,
$$

where $\tilde{u}_{z i}^{G}\left(x, k_{y}, z, \omega\right)$ is the representation in the frequency-wavenumber domain of the Green's function $u_{z i}^{G}(x, y, z, t)$ of the soil that represents the displacement in the direction $\mathbf{e}_{i}$ at a time $t$ in a point $\{x, y, z\}^{\mathrm{T}}$ due to an impulse load $\delta(t)$ in the vertical direction $\mathbf{e}_{z}$ at the origin of the frame of reference.

\subsection{The response to moving loads}

In the fixed frame of reference, the distribution of $n$ vertical axle loads on the coupled track-soil system is written as the summation of the product of Dirac functions that determine the time-dependent position $\left\{x_{S}, y_{k}+v t, z_{S}\right\}^{\mathrm{T}}$ and the time history $g_{k}(t)$ of the $k$ th axle load:

$$
\mathbf{F}(x, y, z, t)=\sum_{k=1}^{n} \delta\left(x-x_{S}\right) \delta\left(y-y_{k}-v t\right) \delta\left(z-z_{S}\right) g_{k}(t) \mathbf{e}_{z},
$$

where $y_{k}$ is the initial position of the $k$ th axle that moves with the train speed $v$ along the $y$-axis and $\mathbf{e}_{z}$ denotes the vertical unit vector.

Accounting for the invariance of the track-soil system in the longitudinal $y$-direction, the Betti-Rayleigh reciprocal theorem allows to derive the following expression for the response $u_{s i}(x, y, z, t)$ at a point $\{x, y, z\}^{\mathrm{T}}$ due to the moving axle loads:

$$
u_{s i}(x, y, z, t)=\sum_{k=1}^{n} \int_{-\infty}^{t} g_{k}(\tau) h_{z i}\left(x, y-y_{k}-v \tau, z, t-\tau\right) \mathrm{d} \tau .
$$

The response due to a moving load on the track can therefore be calculated from the response for a concentrated impulse load at a fixed position $\left\{x_{S}, 0, z_{S}\right\}^{\mathrm{T}}$ on the track. A double forward Fourier transformation allows to derive the following expression in the frequency-wavenumber domain:

$$
\tilde{u}_{s i}\left(x, k_{y}, z, \omega\right)=\sum_{k=1}^{n} \hat{g}_{k}\left(\omega-k_{y} v\right) \tilde{h}_{z i}\left(x, k_{y}, z, \omega\right) \exp \left(+\mathrm{i} k_{y} y_{k}\right)
$$

The frequency shift $k_{y} v$ between the circular frequency at the receiver and at the source corresponds to the Doppler effect.

The frequency content $\hat{u}_{s i}(x, y, z, \omega)$ of the response is computed as the inverse wavenumber domain transformation:

$$
\hat{u}_{s i}(x, y, z, \omega)=\frac{1}{2 \pi} \sum_{k=1}^{n} \int_{-\infty}^{+\infty} \hat{g}_{k}\left(\omega-k_{y} v\right) \tilde{h}_{z i}\left(x, k_{y}, z, \omega\right) \exp \left[-\mathrm{i} k_{y}\left(y-y_{k}\right)\right] \mathrm{d} k_{y} .
$$

A change of variables according to $k_{y}=(\omega-\tilde{\omega}) / v$ moves the frequency shift from the frequency content of the moving load to the wavenumber content of the transfer function:

$$
\hat{u}_{s i}(x, y, z, \omega)=\frac{1}{2 \pi v} \sum_{k=1}^{n} \int_{-\infty}^{+\infty} \hat{g}_{k}(\tilde{\omega}) \tilde{h}_{z i}\left(x, \frac{\omega-\tilde{\omega}}{v}, z, \omega\right) \exp \left[-\mathrm{i}\left(\frac{\omega-\tilde{\omega}}{v}\right)\left(y-y_{k}\right)\right] \mathrm{d} \tilde{\omega} .
$$


The response in the time domain is finally obtained as the inverse Fourier transform with respect to $\omega$. Compared to Eq. (13), this approach offers the advantage that the transfer function is evaluated in the frequency-wavenumber domain.

In the particular case where only the quasi-static contribution is considered, the axle load $g_{k}$ has a constant value $T_{k}$ in time and the frequency content $\hat{g}_{k}(\tilde{\omega})$ equals $T_{k} 2 \pi \delta(\tilde{\omega})$. Eq. (16) can now be elaborated as follows:

$$
\hat{u}_{s i}(x, y, z, \omega)=\sum_{k=1}^{n} T_{k} \exp \left(+\mathrm{i} \frac{\omega}{v} y_{k}\right)\left[\frac{1}{v} \tilde{h}_{z i}\left(x, \frac{\omega}{v}, z, \omega\right) \exp \left(-\mathrm{i} \frac{\omega}{v} y\right)\right],
$$

where the factor between the square brackets is the response due to a single unit axle load with a speed $v$ and an initial position $y=0$. The factor in front represents a modulation of the frequency content that is determined by the train composition and the train speed $v$.

\subsection{The track compliance}

In order to derive the expression for the track compliance matrix $\hat{\mathbf{C}}_{t}$ in Eq. (4), a double inverse Fourier transform of Eq. (14) is used to calculate the response in a moving frame of reference $(x, \hat{y}, z, t)$, with $\hat{y}=y-v t$ :

$$
\begin{aligned}
u_{s i}(x, \hat{y}, z, t)= & \frac{1}{4 \pi^{2}} \int_{\infty}^{+\infty} \int_{-\infty}^{+\infty} \hat{g}_{k}\left(\omega-k_{y} v\right) \tilde{h}_{z i}\left(x, k_{y}, z, \omega\right) \\
& \times \exp \left[-\mathrm{i} k_{y}\left(\hat{y}+v t-y_{k}\right)\right] \exp (+\mathrm{i} \omega t) \mathrm{d} k_{y} \mathrm{~d} \omega .
\end{aligned}
$$

Replacing the circular frequency $\omega$ by $\tilde{\omega}+k_{y} v$ leads to the following expression for the time history of the response:

$$
u_{s i}(x, \hat{y}, z, t)=\frac{1}{2 \pi} \int_{-\infty}^{+\infty} \hat{u}_{s i}(x, \hat{y}, z, \omega) \exp (+\mathrm{i} \tilde{\omega} t) \mathrm{d} \tilde{\omega},
$$

where $\hat{u}_{s i}(x, \hat{y}, z, \tilde{\omega})$ is the frequency content of the response in the moving frame of reference:

$$
\hat{u}_{s i}(x, \hat{y}, z, \omega)=\frac{1}{2 \pi} \int_{-\infty}^{+\infty} \hat{g}_{k}(\tilde{\omega}) \tilde{h}_{z i}\left(x, k_{y}, z, \tilde{\omega}+k_{y} v\right) \exp \left[-\mathrm{i} k_{y}\left(\hat{y}-y_{k}\right)\right] \mathrm{d} k_{y}
$$

This expression is now used to calculate the element $\hat{C}_{l k}^{t}(\tilde{\omega})$ of the track compliance matrix from the rail response $\tilde{u}_{r}\left(x, k_{y}, z, \tilde{\omega}\right)$ in the frequency-wavenumber domain as

$$
\hat{C}_{l k}^{t}(\tilde{\omega})=\frac{1}{2 \pi} \int_{-\infty}^{+\infty} \tilde{u}_{r}\left(x, k_{y}, z, \tilde{\omega}+k_{y} v\right) \exp \left[-\mathrm{i} k_{y}\left(y_{l}-y_{k}\right)\right] \mathrm{d} k_{y},
$$

which represents the Fourier transform of the track response at the time-dependent position of axle $l$ due to a unit impulse at axle $k$. The track compliance matrix $\hat{\mathbf{C}}_{t}$ is not symmetric due to the motion of the contact points [12].

\section{The transfer functions in the free field}

\subsection{Determination of the dynamic soil characteristics}

In order to determine the soil layering and the small strain dynamic soil characteristics, two SASW tests [25] and five SCPT [36] have been performed at the test site, which is located on a field in Lincent along the HST track Brussels-Köln.

The SASW method is a non-invasive geophysical prospection method to determine the dynamic shear modulus of shallow soil layers that is based on the dispersive characteristics of surface waves in a layered medium $[23,24]$. The SASW method involves an in situ experiment where vibrations are generated at the soil's surface. The response in the free field is used to determine the experimental dispersion curve which is associated with the first surface wave. Next, an inverse problem is formulated as a nonlinear least-squares 
problem, where the shear wave velocity $C_{s}$ and the thickness of the soil layers are determined so that the difference between the experimental and the theoretical dispersion curve is minimized. This optimization problem is solved for a horizontally layered half-space with an increasing number of layers until a satisfactory agreement of both dispersion curves is obtained.

At the test site, two experimental set-ups have been used for the SASW tests [25]. In set-up 1, a mass of $110 \mathrm{~kg}$ is dropped from a height of $0.9 \mathrm{~m}$ on a square steel foundation with a width of $0.7 \mathrm{~m}$ and a mass of $480 \mathrm{~kg}$. A dashpot is used to control the frequency content of the loading and to prevent rebound of the mass. Three force sensors are installed immediately below the dashpot as to measure the impact force on the foundation. In set-up 2, a larger impact mass of $550 \mathrm{~kg}$ falling from a height of $0.85 \mathrm{~m}$ on a circular steel plate has been used to generate a larger impact and surface waves with a longer wavelength.

Figs. $3 \mathrm{a}$ and $\mathrm{b}$ compare the experimental dispersion curve with the theoretical dispersion curve for both setups. It is found that the site consists of a layer with a thickness of $3.0 \mathrm{~m}$ and a shear wave velocity between 150 and $160 \mathrm{~m} / \mathrm{s}$ and a layer with a shear wave velocity between 250 and $280 \mathrm{~m} / \mathrm{s}$ [25]. The results of the SCPT tests confirm these observations [36]. Further research is needed to derive reliable estimates of the material damping ratio from these tests. In the following subsection, it is shown how a fit between the experimental and numerical soil transfer functions has been used to estimate a value of 0.03 for the material damping ratio $\beta$ of all soil layers, both in deviatoric and volumetric deformation. Furthermore, a value of $\frac{1}{3}$ has been assumed for the Poisson's ratio and a density $\rho$ equal to $2000 \mathrm{~kg} / \mathrm{m}^{3}$. Table 1 summarizes the dynamic soil characteristics of the site in Lincent.

\subsection{Validation of the transfer functions in the free field}

As the determination of the dynamic soil characteristics only relies on the correspondence between the experimental and theoretical dispersion curve of the first surface wave, the measured impact force and response in the SASW test allows for an additional validation of the layered half-space model as presented in Table 1. The experimental mobility function $\hat{M}_{z}(\omega)$ is defined as the ratio between the measured free field velocity and the impact force. The theoretical mobility function has been computed for the soil model in
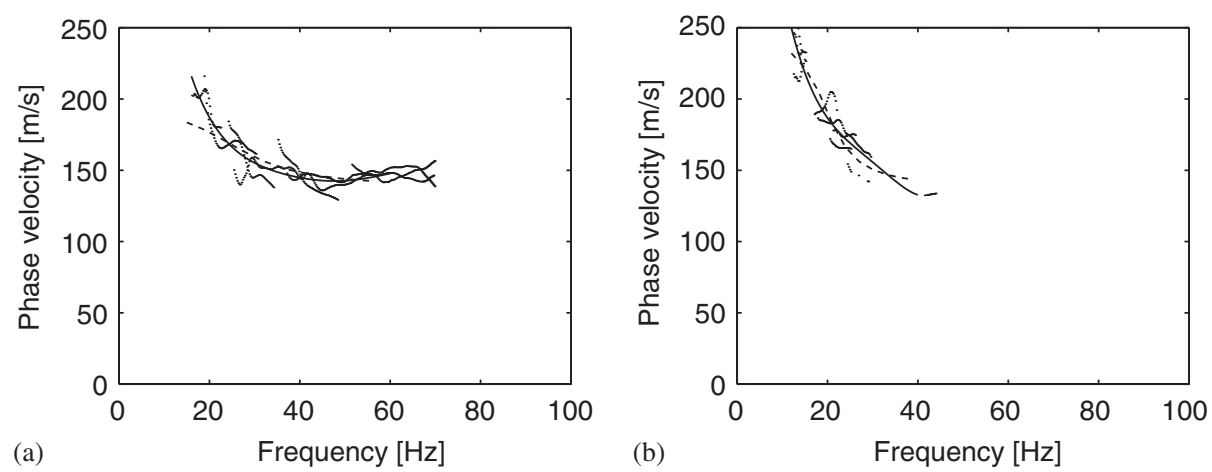

Fig. 3. Experimental dispersion points, fitted experimental dispersion curve (solid line) and theoretical dispersion curve for the case of three layers on a half-space (dashed line) in (a) set-up 1 and (b) set-up 2.

Table 1

Dynamic soil characteristics

\begin{tabular}{lllllll}
\hline Layer & $d(\mathrm{~m})$ & $C_{s}(\mathrm{~m} / \mathrm{s})$ & $C_{p}(\mathrm{~m} / \mathrm{s})$ & $E\left(\times 10^{6} \mathrm{~N} / \mathrm{m}^{2}\right)$ & $v$ & $\rho\left(\mathrm{kg} / \mathrm{m}^{3}\right)$ \\
\hline 1 & 3 & 150 & 300 & 120 & 0.333 & 2000 \\
2 & $\infty$ & 280 & 560 & 418 & 0.333 & 2000 \\
\hline
\end{tabular}



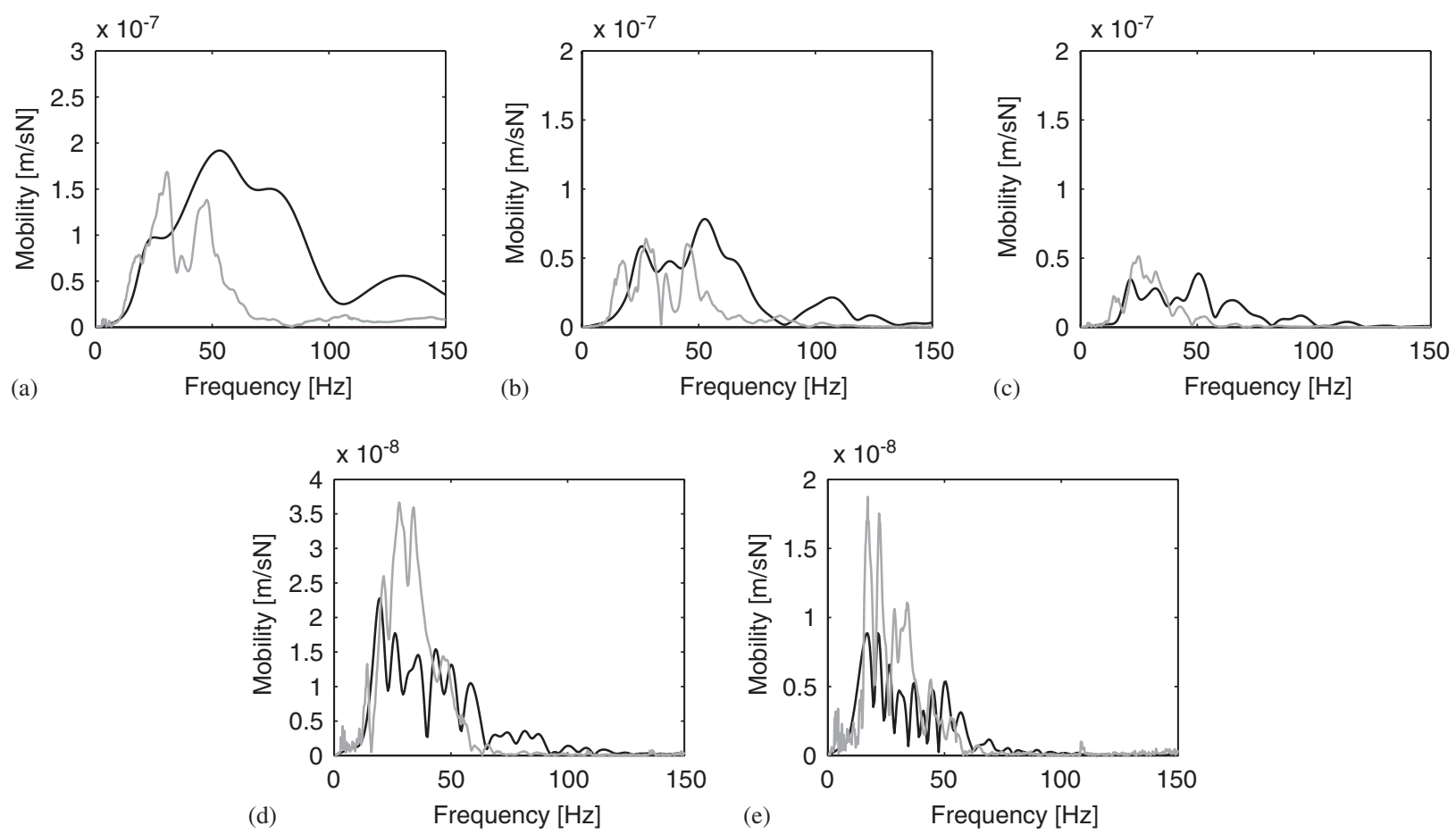

Fig. 4. The experimental (grey line) and computed (black line) mobility between the foundation and the free field at a distance of: (a) $8 \mathrm{~m}$; (b) $16 \mathrm{~m}$; (c) $24 \mathrm{~m}$; (d) $32 \mathrm{~m}$; and (e) $48 \mathrm{~m}$ from the foundation.

Table 1 using a subdomain formulation for dynamic soil-structure interaction [37,38]. The foundation is modelled as a rigid plate, while the impedance of the soil is modelled with a boundary element formulation.

Fig. 4 compares the experimental and computed mobility at 8,16,24,32, and $48 \mathrm{~m}$ from the source. A fit of the experimental and numerical results at large distances and high frequencies has been used to determine the material damping ratio $\beta$ of the soil layers in Table 1 . The general agreement between both results is acceptable. However, some discrepancy remains that cannot be explained by a wrong estimation of the material damping ratio. A clear overestimation is found in the near field at distances between 8 and $24 \mathrm{~m}$ and frequencies higher than $50 \mathrm{~Hz}$, whereas these numerical results are relatively insensitive to the material damping ratio. Furthermore, a cut-off frequency around $50 \mathrm{~Hz}$ seems to be present in the experimental results that cannot be explained by the theoretical model. Similar discrepancies between measured and computed soil transfer functions have been reported by Auersch [39].

\section{The transfer functions between the track and the free field}

\subsection{Determination of the dynamic track characteristics}

The track in Lincent is a classical ballasted track with UIC 60 rails supported every $0.60 \mathrm{~m}$ by rubber pads on monoblock concrete sleepers. The rails are continuously welded and are fixed with a Pandrol E2039 rail fastening system and supported by resilient studded rubber rail pads (type 5197) with a thickness of $11 \mathrm{~mm}$. Each rail pad is preloaded with a clip toe load of about $20 \mathrm{kN}$ per rail seat. The prestressed concrete monoblock sleepers have a length $l_{\mathrm{sl}}=2.50 \mathrm{~m}$, a width $b_{\mathrm{sl}}=0.235 \mathrm{~m}$, a height $h_{\mathrm{sl}}=0.205 \mathrm{~m}$ (under the rail) and a mass $m_{\mathrm{sl}}=300 \mathrm{~kg}$. The track is supported by a porphyry ballast layer (calibre $\frac{25}{50}$, thickness $d=0.35 \mathrm{~m}$ ) and a limestone sub-ballast layer (thickness $d=0.60 \mathrm{~m}$ ). The density of these ballast layers is $1700 \mathrm{~kg} / \mathrm{m}^{3}$. Below the ballast, the soil has been improved over a depth of $1.0 \mathrm{~m}$ by means of lime. 
The track is modelled as a longitudinally invariant track, where the dynamic stiffness of the rail pads and the mass of the sleepers are uniformly distributed along the track. It is assumed that the presence of the second track does not influence the vibrations in the free field, so that a single track model can be applied. The width of the track-soil interface in the model is $2.5 \mathrm{~m}$ and corresponds to the length of the sleepers. As the dynamics of the track are considered in a relatively low frequency range from 0 to $400 \mathrm{~Hz}$, the Euler-Bernoulli beam theory can be applied to model the rails [29]. The rails have a bending stiffness $E_{r} I_{r}=6.45 \times 10^{6} \mathrm{Nm}^{2}$ and a mass per unit length $\rho_{r} A_{r}=60.3 \mathrm{~kg} / \mathrm{m}$ for each rail. The track gauge $l_{2}-l_{1}$ is $1.435 \mathrm{~m}$. The distributed sleeper mass per unit length $\bar{m}_{s l}$ equals $500 \mathrm{~kg} / \mathrm{m}$.

In the track model, the porphyry ballast layer with a height $h_{b}$ of $0.35 \mathrm{~m}$ and a density $\rho_{b}$ of $1700 \mathrm{~kg} / \mathrm{m}^{3}$ is included. The equivalent ballast mass $\bar{m}_{b}$ in the continuous model is calculated from the part of the ballast that is in contact with the sleepers as $\rho_{b} h_{b} l_{\mathrm{sl}} b_{\mathrm{sl}} / d$. The dynamic stiffness $\bar{k}_{b}$ and damping $\bar{c}_{b}$ of the ballast and the equivalent stiffness $\bar{k}_{\mathrm{rp}}=k_{\mathrm{rp}} / d$ and damping $\bar{c}_{\mathrm{rp}}=c_{\mathrm{rp}} / d$ of the rail pad are obtained by means of a rail receptance test. For a correct identification of the track properties, it is important to apply a model that accounts for dynamic track-soil interaction, which has an important influence on the dynamic track behaviour upto $200 \mathrm{~Hz}$, as indicated by Knothe and $\mathrm{Wu}$ [30]. The soil characteristics in Table 1 are used to calculate the soil impedance matrix $\tilde{\mathbf{K}}_{s}$. The thickness of the top layer is decreased from 3 to $2 \mathrm{~m}$ to simulate the fact that the track is partially embedded in the soil. For the calculation of the rail receptance, Eq. (8) is solved with a track force vector $\tilde{\mathbf{f}}_{\text {tr }}$ equal to $\{1,0,0,0,0,0\}^{\mathrm{T}}$, that corresponds to a unit impulse loading on a single rail. The track response $\hat{\mathbf{u}}_{\mathrm{tr}}(y, \omega)$ at an arbitrary position $y$ along the track is obtained as the inverse wavenumber transformation of the track displacement vector $\tilde{\mathbf{u}}_{\mathrm{tr}}\left(k_{y}, \omega\right)$. The track receptance corresponds to the response at the point $y=0$ where the force is applied.

The unknown track characteristics $\left\{\bar{k}_{\mathrm{rp}}, \bar{c}_{\mathrm{rp}}, \bar{k}_{b}, \bar{c}_{b}\right\}^{\mathrm{T}}$ are now determined by the solution of a nonlinear leastsquares optimization problem with a residual that is a function of the track characteristics. For the determination of the dynamic stiffness of the ballast, the discrepancy between the experimental and computed rail receptance is minimized in the frequency range between 50 and $200 \mathrm{~Hz}$. The experimental rail receptance has been determined in loaded track conditions, by means of an excitation of the rail at a sleeper position. In the calculation of the residual, only those experimental values with a coherence larger than 0.95 have been considered. The ballast stiffness $\bar{k}_{b}$ and damping $\bar{c}_{b}$ are estimated as $1534.5 \times 10^{6} \mathrm{~N} / \mathrm{m}^{2}$ and $27.7 \times 10^{3} \mathrm{Ns} / \mathrm{m}^{2}$, respectively. This corresponds to a vertical ballast stiffness $k_{b}$ per sleeper of $920.7 \times 10^{6} \mathrm{~N} / \mathrm{m}$ and damping $c_{b}$ of $16.6 \times 10^{3} \mathrm{Ns} / \mathrm{m}$. If the limited support area $l_{\mathrm{sl}} b_{\mathrm{sl}}$ of the sleeper is accounted for, this results in a ballast stiffness $K_{b}=1567 \times 10^{6} \mathrm{~N} / \mathrm{m}^{3}$ or a Young's modulus $E_{b}=K_{b} h_{b}=548.5 \times 10^{6} \mathrm{~N} / \mathrm{m}^{2}$.

Based on an updating of the rail receptance in a frequency range between 200 and $400 \mathrm{~Hz}$, the equivalent rail pad stiffness $\bar{k}_{\mathrm{rp}}$ is estimated as $255.7 \times 10^{6} \mathrm{~N} / \mathrm{m}^{2}$, while a value of $22.5 \times 10^{3} \mathrm{Ns} / \mathrm{m}^{2}$ is found for the rail pad damping $\bar{c}_{\mathrm{rp}}$. This corresponds to a rail pad stiffness $k_{\mathrm{rp}}=153.4 \times 10^{6} \mathrm{~N} / \mathrm{m}$, as for medium to stiff rail pads, and a damping $c_{\mathrm{rp}}=13.5 \times 10^{3} \mathrm{Ns} / \mathrm{m}$.

\subsection{Validation of the track receptance}

Fig. 5a shows the final agreement between the modulus of the experimental and the numerical rail receptance. The first peak near $25 \mathrm{~Hz}$ falls below the range of frequencies considered in the inverse analysis and is due to the soil stratification, where a relatively soft layer overlays a stiffer half-space. The peak near $350 \mathrm{~Hz}$ corresponds to the resonance of the rail on the rail pad and the ballast. This is the cut-on frequency of the bending waves in the rail.

As only the modulus of the rail receptance has been used to define the residual in the least-squares optimization problem, it is useful to verify the agreement between the phase of the experimental and numerical rail receptance (Fig. 5b), as well as the response of the sleeper underneath the rail (Fig. 6). The most important discrepancy is observed at very low frequencies, where the dynamic soil characteristics have a large influence on the rail receptance [30]. The results seem to indicate an underestimation of the frequency at which the first peak occurs. This could be due to fact that the presence of the sub-ballast layer and the improved soil conditions are not accounted for in the numerical model. The overall trends, however, are well predicted and, although only the modulus of the rail receptance has been used in the inverse analysis, a good agreement is also obtained for the phase of the rail and the sleeper response. 

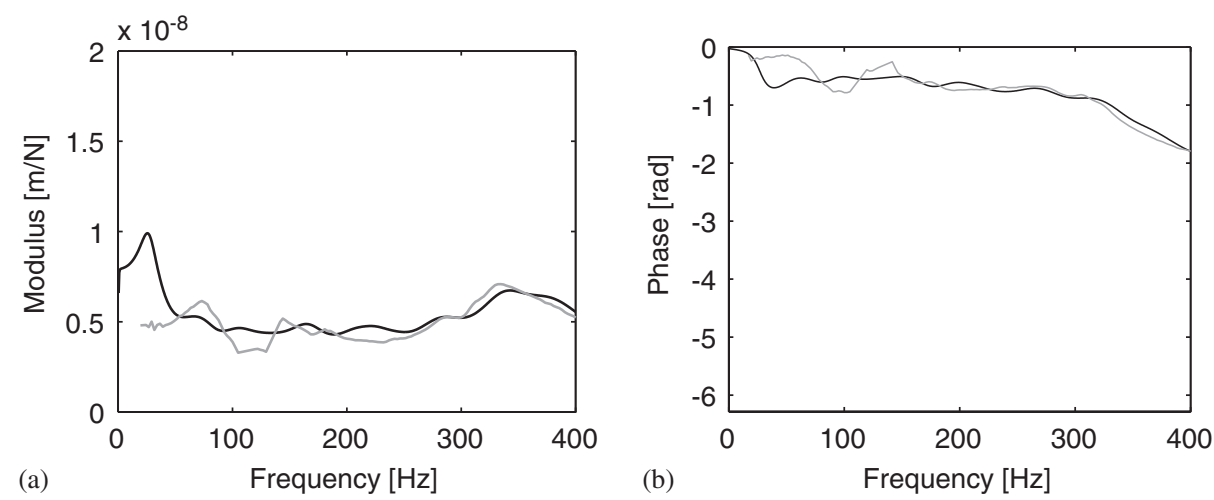

Fig. 5. The experimental (grey line) and computed (black line): (a) modulus and (b) phase of the rail receptance $\hat{u}_{r 1}$.
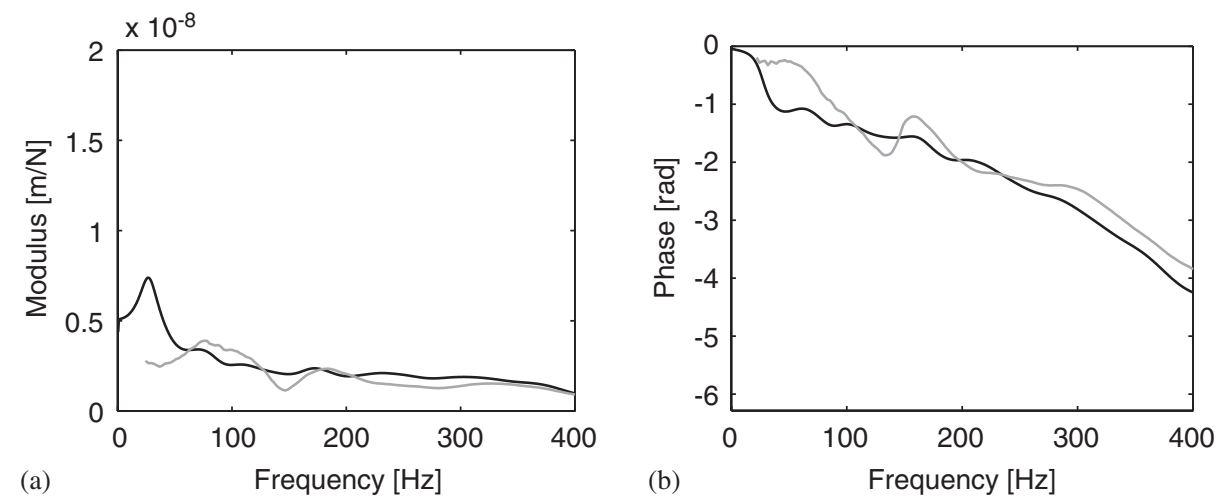

Fig. 6. The experimental (grey line) and computed (black line): (a) modulus and (b) phase of the sleeper response $\hat{u}_{\mathrm{sl}}+l_{1} \beta_{\mathrm{sl}}$ underneath the rail.

\subsection{Validation of the transfer functions between the track and the free field}

Within the frame of the measurement campaign, the transfer functions between the track and the free field have been obtained from several impacts of a falling weight [26]. These experimental results can now be used to validate the numerical model.

For the calculation of the transfer functions between the track and the free field, the track force vector $\tilde{\mathbf{f}}_{\mathrm{tr}}$ is equal to $\{1,0,0,0,0,0\}^{\mathrm{T}}$, corresponding to a unit impulse excitation on a single rail. Eqs. (8) and (10) are used to calculate the response at the track-soil interface and the soil tractions at the interface, respectively. Next, the transfer functions between the track and the free field are calculated in the frequency-wavenumber domain by means of Eq. (11). Since for the calculation of the track response, the thickness of the top layer has been reduced from 3 to $2 \mathrm{~m}$, the tractions are now applied at a depth of $1 \mathrm{~m}$ in the original soil model and the response at the soil's surface is calculated. An inverse Fourier transform from the wavenumber domain $k_{y}$ to the spatial coordinate $y$ allows to compute the free field velocities.

Fig. 7 compares the experimental and computed mobility functions at a distance of $8,16,24,32,48$, and $64 \mathrm{~m}$ from the track. At all distances from the track, the response is overestimated. Compared to the validation of the foundation-soil transfer functions in Fig. 4, however, a better agreement is obtained, as the experimental and computed track-free field transfer functions show a similar frequency dependence. At 8 and $16 \mathrm{~m}$, the response has a broad frequency content upto $150 \mathrm{~Hz}$, whereas at larger distances, the frequency content becomes more concentrated at low frequencies, with a maximum around $20 \mathrm{~Hz}$. As for the validation of the foundation-soil transfer functions in Fig. 4, the best agreement is obtained at larger distances from the track. The fact that the agreement between experimental and computed results changes with the distance from the 

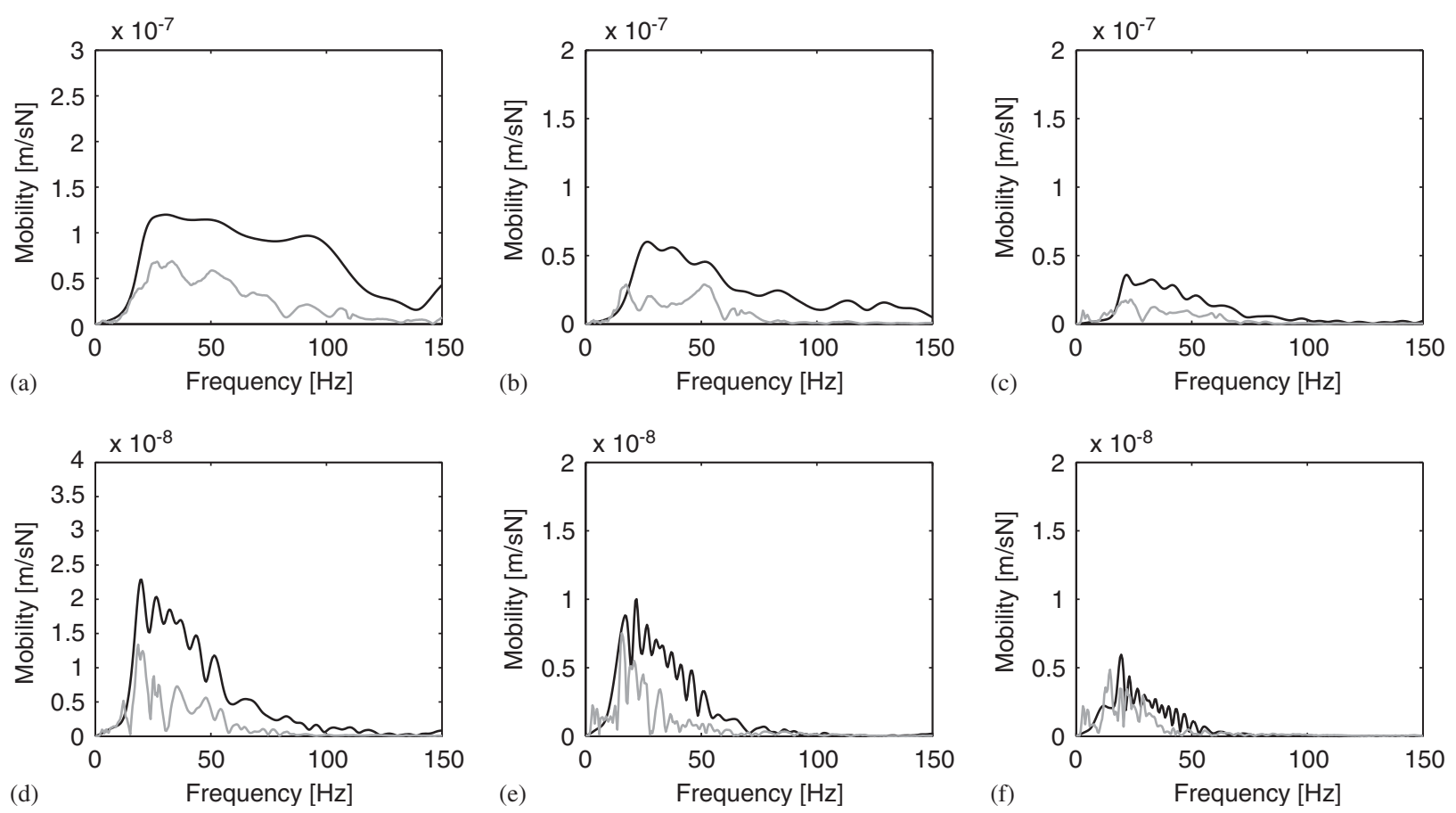

Fig. 7. The experimental (grey line) and computed (black line) mobility between the track and the free field at a distance of: (a) $8 \mathrm{~m}$; (b) $16 \mathrm{~m}$; (c) $24 \mathrm{~m}$; (d) $32 \mathrm{~m}$; (e) $48 \mathrm{~m}$; and (f) $64 \mathrm{~m}$ from the track.

track might be due to a wrong estimation of the material damping ratio that has a large influence in a broad range of frequencies at large distances.

\section{The track and free field response due to the passage of a Thalys HST}

\subsection{Determination of the train characteristics}

The Thalys HST (Fig. 8) consists of two locomotives and eight carriages; the total length of the train is equal to $200.18 \mathrm{~m}$. The locomotives are supported by two bogies and have four axles. The carriages next to the locomotives share one bogie with the neighbouring carriage, while the six other carriages share both bogies with neighbouring carriages. The total number of bogies equals 13 and, consequently, the number of axles on the train is 26 . The carriage length $L_{t}$, the distance $L_{b}$ between bogies, the axle distance $L_{a}$, the total axle mass $M_{t}$, the sprung axle mass $M_{s}$ and the unsprung axle mass $M_{u}$ of all carriages are summarized in Table 2.

In the following, this model will be used for the calculation of the sleeper response and the free field vibrations during the passage of a Thalys HST at two train speeds of 218 and $294 \mathrm{~km} / \mathrm{h}$. First, the sleeper response is considered. For this case, only the quasi-static contribution to the response is taken into account. The quasi-static contribution depends only on the total axle mass $M_{t}$ in Table 2. Second, the free field vibrations are considered. Whereas the quasi-static contribution dominates the track response, this is no longer the case for the free field response, as the train speeds are relatively low compared to the shear wave velocity of $150 \mathrm{~m} / \mathrm{s}$ of the top layer. The quasi-static contribution is neglected and only the dynamic axle loads are taken into account. The dynamic axle loads are calculated by means of Eq. (5) from the vehicle compliance, the track compliance matrix in a moving frame of reference and the frequency content $\hat{\mathbf{u}}_{w / r}$ of the track unevenness. Furthermore, the interaction between the train and the track is discussed in more detail and the need for a coupled train-track model is investigated. Finally, the dynamic axle loads are used to calculate the vibrations during the passage of a Thalys HST and the experimental and computed results for the free field response are discussed. 


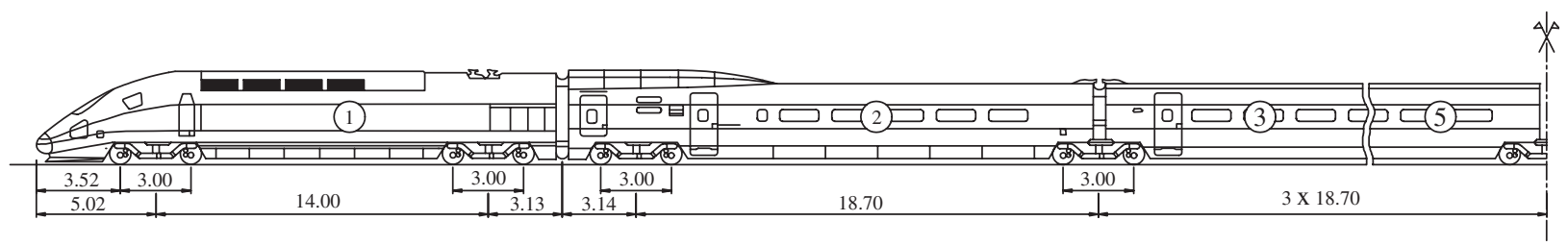

Fig. 8. The configuration of the Thalys HST.

Table 2

Geometrical and mass characteristics of the Thalys HST

\begin{tabular}{llllll}
\hline & $L_{t}(\mathrm{~m})$ & $L_{b}(\mathrm{~m})$ & $L_{a}(\mathrm{~m})$ & $M_{t}(\mathrm{~kg})$ & $M_{s}(\mathrm{~kg})$ \\
\hline Locomotives & 22.15 & 14.00 & 3.00 & 17000 & 14937 \\
Side coach & 21.84 & 18.70 & 3.00 & 17000 & 14937 \\
Central coach & 18.70 & 18.70 & 3.00 & 17000 & 14937 \\
\hline
\end{tabular}

\subsection{Validation of the track response}

Fig. 9a shows the frequency content of the experimental and computed velocity of the sleeper during the passage of the Thalys HST at $294 \mathrm{~km} / \mathrm{h}$. Although the locomotives and the adjacent carriages have a different axle composition than the six central carriages, a modulation of the frequency content is observed with peaks at the fundamental bogie passage frequency $f_{b}=v / L_{b}=4.4 \mathrm{~Hz}$ of the central carriages and its higher harmonics, modulated at the axle passage frequency $f_{a}=v / L_{a}=27.2 \mathrm{~Hz}$ [40]. An excellent agreement between the experimental and computed results is obtained at low frequencies, while the experimental response is slightly overestimated at frequencies between 20 and $60 \mathrm{~Hz}$ and underestimated at higher frequencies due to the neglection of the dynamic axle loads. The identification of the track characteristics in loaded track conditions has shown to be crucial for a good prediction of the sleeper response.

Fig. $9 \mathrm{~b}$ shows the time history of the experimental and computed velocity of the sleeper during the passage of the Thalys HST at a speed $v$ of $294 \mathrm{~km} / \mathrm{h}$. The passage of every axle can clearly be identified from the time history of the response that shows a nearly uniform response for every axle load. A detailed inspection of the experimental response reveals a more irregular time history, which is not present in the computed results due to the fact that the dynamic component of the axle loads has been neglected in the calculation of the track response.

Fig. 10 shows the time history and frequency content of the experimental and computed velocity of the sleeper during the passage of the Thalys HST at a speed $v$ of $218 \mathrm{~km} / \mathrm{h}$. Both the experimental and computed results show how at this lower train speed, the frequency content has shifted to lower frequencies and the maximum sleeper velocity has decreased.

\subsection{Determination of the track unevenness}

Shortly before the homologation tests, the Belgian Railway Company NMBS has used an EM-130 track recording car to measure the initial track unevenness [41]. The measuring bandwidth of track recording cars is generally restricted to wavelengths ranging from a few metres to 20 or $30 \mathrm{~m}$ [42], as can be observed from the transfer function of the EM-130 recording vehicle [41]. The measured power spectral density (PSD) function [43] has therefore been fitted by the following PSD function in the range of wavelengths between 6 and $24 \mathrm{~m}$ :

$$
\tilde{S}_{u_{w / r}}\left(k_{y}\right)=\tilde{S}_{u_{w / r}}\left(k_{y 0}\right)\left(\frac{k_{y}}{k_{y 0}}\right)^{-w},
$$



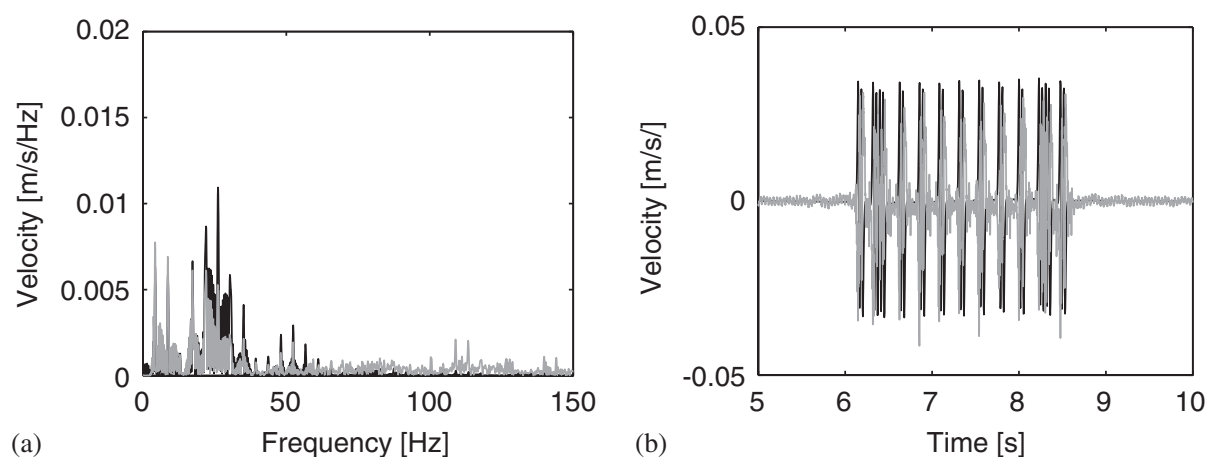

Fig. 9. The experimental (grey line) and computed (black line): (a) frequency content and (b) time history of the sleeper response during the passage of the Thalys HST at a speed $v$ of $294 \mathrm{~km} / \mathrm{h}$.
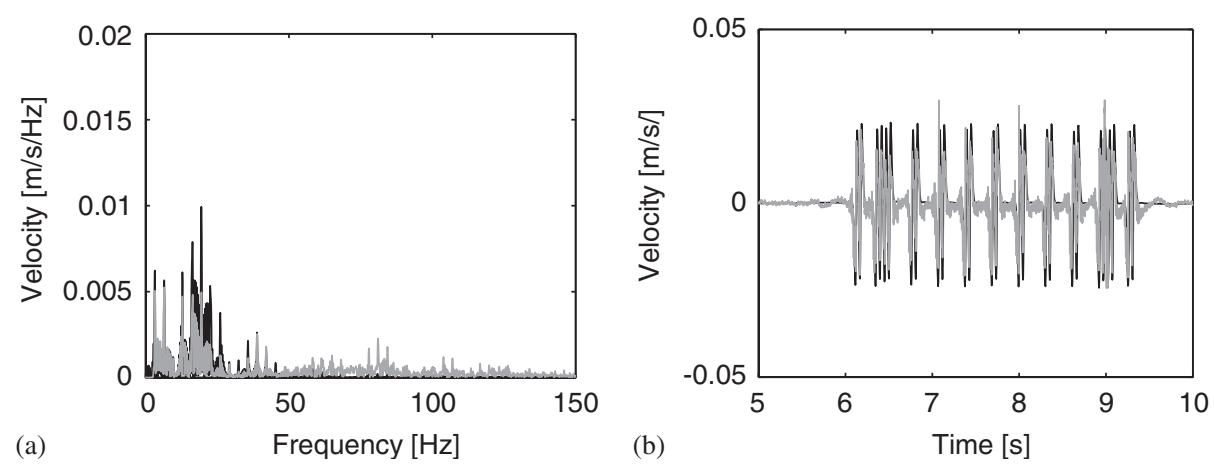

Fig. 10. The experimental (grey line) and computed (black line): (a) frequency content and (b) time history of the sleeper response during the passage of the Thalys HST at a speed $v$ of $218 \mathrm{~km} / \mathrm{h}$.

with $k_{y 0}=1 \mathrm{rad} / \mathrm{m}$ and $w=3.5$, as commonly assumed for railway unevenness. A value of $1.36 \times 10^{-8} \mathrm{~m}^{3}$ has been found for $\tilde{S}_{u_{w / r}}\left(k_{y 0}\right)$.

Fig. 11 shows the experimental PSD for the right rail of the HST track at the measurement site in Lincent, as well as the fitted PSD function. Furthermore, an upper and a lower bound for the PSD functions of the rail unevenness [43] have been added with a similar dependency on the wavenumber but different reference values of $5 \times 10^{-7}$ and $1 \times 10^{-9} \mathrm{~m}^{3}$ for $\tilde{S}_{u_{w / r}}\left(k_{y 0}\right)$, respectively.

At a train speed $v$ of $294 \mathrm{~km} / \mathrm{h}$, the range of wavelengths where the PSD has been fit corresponds to an excitation of the vehicle's axles in the frequency range between 3 and $10 \mathrm{~Hz}$. All results for higher frequencies are therefore based on extrapolated values of the fitted PSD. A complementary measurement, with a range of wavelengths between 0.5 and $8 \mathrm{~m}$ that corresponds to the excitation between 10 and $160 \mathrm{~Hz}$ would therefore have been more suitable for the prediction of the free field vibrations.

The PSD $\hat{S}_{w / r}(\omega)$ of the unevenness in the frequency domain is equal to $1 / v \tilde{S}_{w / r}(-\omega / v)$. Accounting for the exponent $w=3.5$ in Eq. (22), the PSD in the frequency domain increases uniformly and proportional to $v^{2.5}$. An increasing train speed is therefore expected to give rise to higher dynamic axle loads and higher vibration levels in the free field.

\subsection{Dynamic behaviour of the coupled train-track system}

The train-track interaction forces are calculated by means of Eq. (5) from the vehicle compliance matrix $\hat{\mathbf{C}}_{v}$, the track compliance matrix $\hat{\mathbf{C}}_{t}$ and the frequency content $\hat{\mathbf{u}}_{w / r}$ of the track unevenness. 


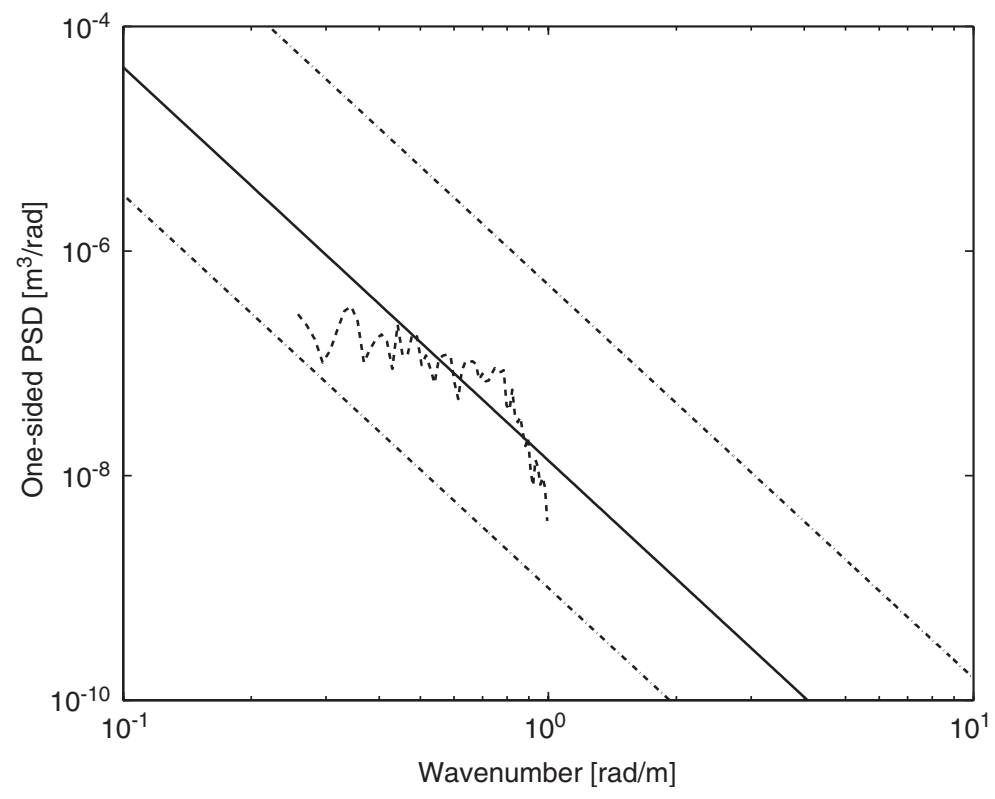

Fig. 11. The experimental (dashed line) and fitted (solid line) PSD of the unevenness on the right rail.

At frequencies of more than a few Hertz [29], the vehicle's primary and secondary suspension isolate the body and the bogie from the wheelset. The vehicle's unsprung mass is therefore the only component that affects the vertical dynamic loads and can be satisfactorily represented as a rigid body [29]. Furthermore, the influence of the primary suspension is small at frequencies higher than $10 \mathrm{~Hz}$, so that each axle can be modelled as a point mass $M_{u}$ and the vehicle compliance matrix is equal to the diagonal matrix $\hat{\mathbf{C}}^{v}=\operatorname{diag}\left\{-1 / M_{u} \omega^{2}\right\}$ of order 26 .

The track compliance in a moving frame of reference is calculated from the rail impulse response in the frequency-wavenumber domain using Eq. (21). As a 2D vehicle model is used, the train loads are distributed equally on both rails and the rail impulse response is found from the solution of the track-soil interaction (8) with a track force vector $\tilde{\mathbf{f}}_{\text {tr }}$ equal to $\{0.5,0.5,0,0,0,0\}^{\mathrm{T}}$.

The influence of the train speed on the track compliance is shown in Fig. 12 where the modulus of the diagonal elements of the track compliance matrix $\hat{\mathbf{C}}_{t}$ is compared for train speeds of 294,218 and $0 \mathrm{~km} / \mathrm{h}$. At a zero train speed, the track compliance shows a similar behaviour as the track receptance in Fig. 5. The difference between both is due to the fact that the impulse excitation is now applied on two rails instead of one. The resonance frequency near $25 \mathrm{~Hz}$ shifts to lower frequencies as the train speed increases, which is due to the Doppler effect.

In order to investigate the behaviour of the coupled vehicle-track system, Eq. (5) is now solved for a vehicle speed $v$ of $294 \mathrm{~km} / \mathrm{h}$ and a unit impulse excitation at the rear axle of the Thalys HST only. Fig. 13 shows the vehicle and the track response at the position of the rear axle. For a unit impulse excitation at the rear axle, the difference between the vehicle displacement $\hat{u}_{c}$ and the track displacement $\hat{u}_{r}$ at this axle, is equal to 1 in the entire frequency domain. The coupled vehicle-track system behaves in a similar way as a single degree of freedom (SDOF) sprung mass system, where a displacement is imposed between the mass and the spring.

At low frequencies, the inertia of the mass is relatively small, so that the displacement $\hat{u}_{c}$ of the mass is equal to the imposed unit differential displacement and $\hat{u}_{r}=0$, as observed in Fig. 13. The imaginary part that corresponds to an out-of-phase response is small. At limiting high frequencies, the displacement of the mass tends to zero, so that $\hat{u}_{c}=0$ and the track displacement $\hat{u}_{r}=-1$. At the resonance frequency of the SDOF system, the unit displacement is taken by the mass, while the imaginary part of both reaches a maximum. For the coupled train-track system, this occurs at a frequency near $75 \mathrm{~Hz}$.

Sheng et al. [12] have recently studied the train-track interaction with a more elaborated single-axle vehicle model that includes the suspended mass, and show that the influence of this suspended mass can be neglected. 


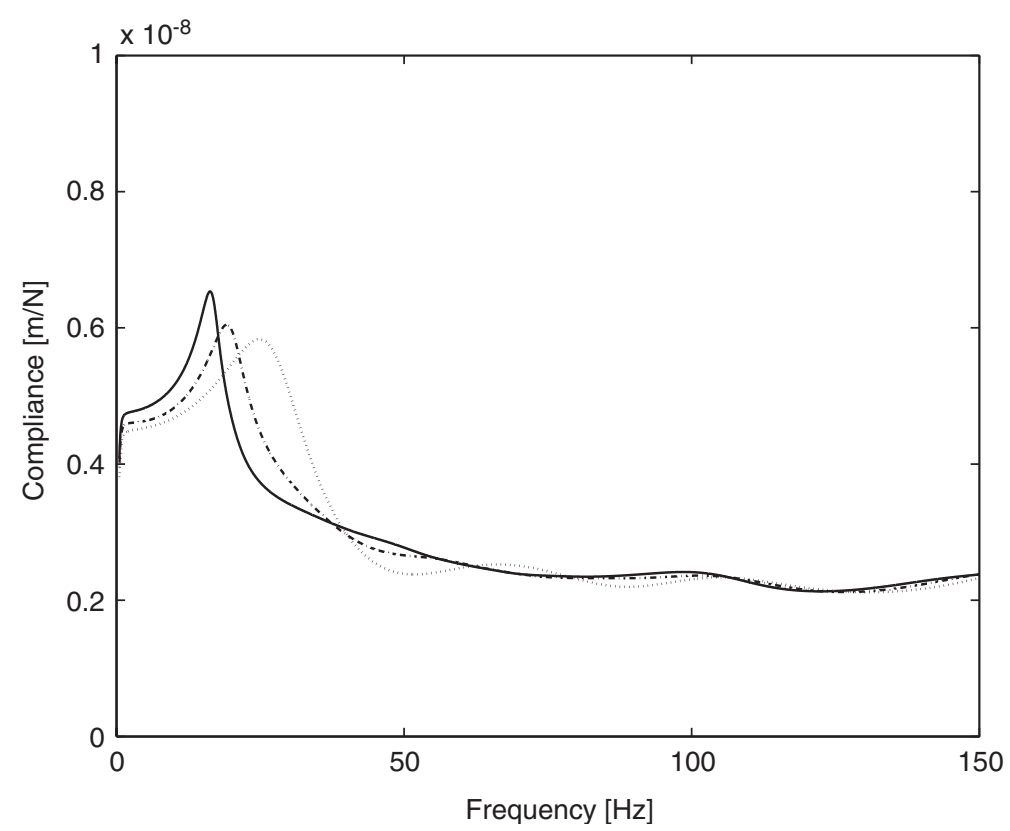

Fig. 12. The modulus of the diagonal elements of the track compliance matrix $\hat{\mathbf{C}}_{t}$ for a train speed of $0 \mathrm{~km} / \mathrm{h}(\mathrm{dotted}$ line $), 218 \mathrm{~km} / \mathrm{h}$ (dashed-dotted line) and $294 \mathrm{~km} / \mathrm{h}$ (solid line).
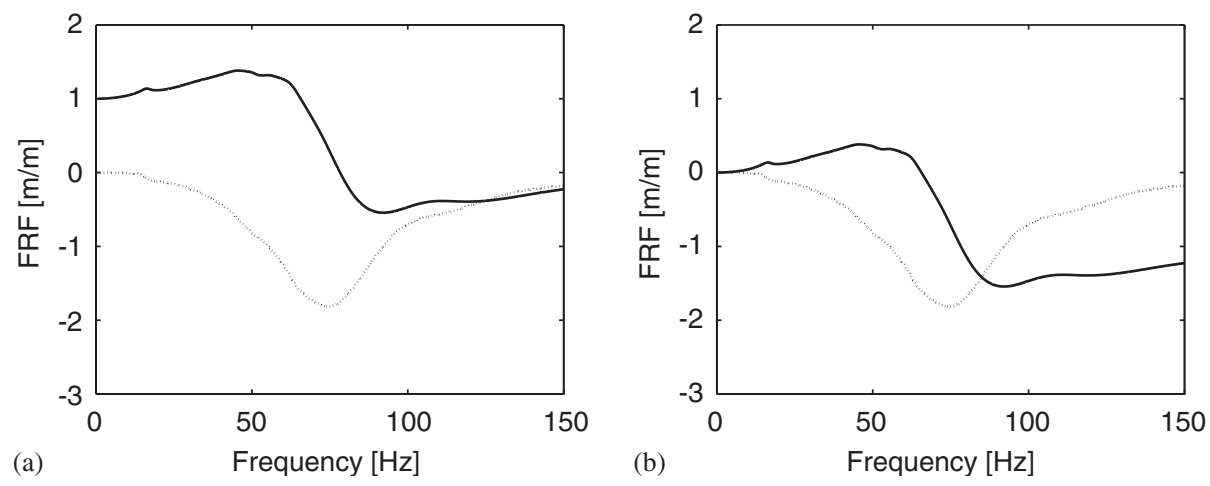

Fig. 13. Real (solid line) and imaginary (dotted line) part of: (a) the displacement $\hat{u}_{c}$ of the vehicle's contact point and (b) the displacement $\hat{u}_{r}$ of the rail for a unit impulse excitation.

\subsection{The train-track interaction forces}

Eq. (5) is now used to compute the train-track interaction forces for a passage of the Thalys HST with a speed of $294 \mathrm{~km} / \mathrm{h}$. The fitted PSD function in Fig. 11 is used to generate an artificial profile $u_{w / r}(y)$ as a Gaussian random process that consists of a superposition of sine functions with random phase angles [44]. The frequency content $\hat{\mathbf{u}}_{w / r}(\omega)$ of the track unevenness in Eq. (5) is calculated from the wavenumber domain representation $\tilde{u}_{w / r}\left(k_{y}\right)$ of this profile $u_{w / r}(y)$ according to Eq. (6).

Fig. 14 shows the frequency content of the train-track interaction force at the front and rear axle of the Thalys HST. The frequency content of these forces exhibits a clear maximum near the train-track resonance frequency that has been observed in Fig. 13.

Fig. 15 shows the frequency content of the dynamic axle loads for a lower train speed of $218 \mathrm{~km} / \mathrm{h}$. In Eq. (5), both the track compliance $\hat{\mathbf{C}}^{t}$ and the track unevenness $\hat{\mathbf{u}}_{w / r}$ depend on the train speed. In the 

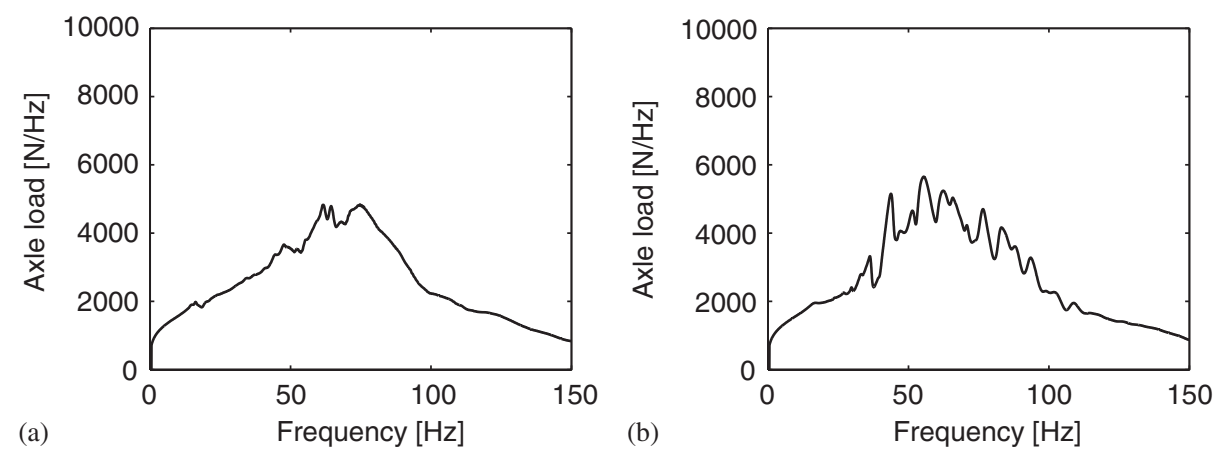

Fig. 14. Frequency content of the train-track interaction force at: (a) the front axle and (b) the rear axle of the Thalys HST for a train-speed of $294 \mathrm{~km} / \mathrm{h}$.
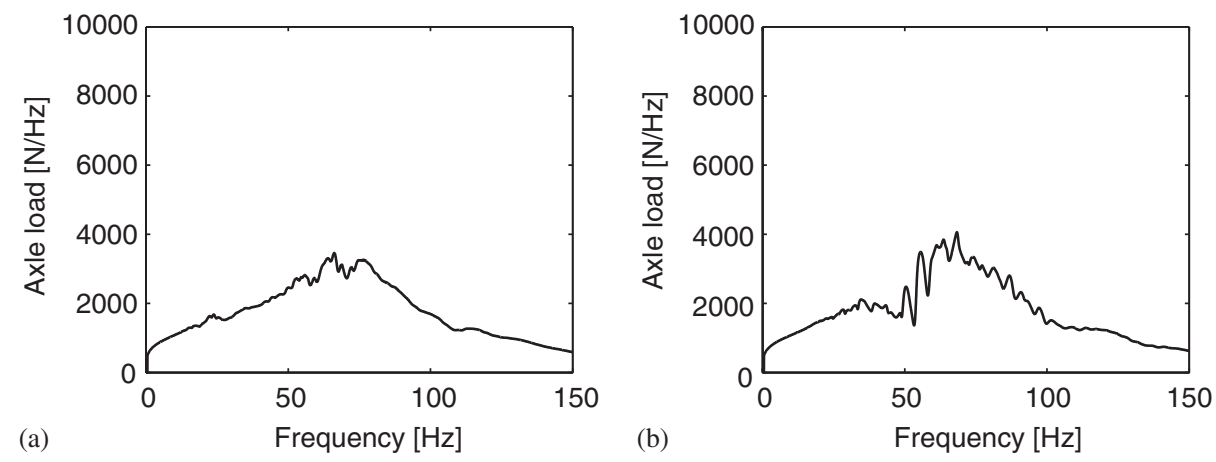

Fig. 15. Frequency content of the train-track interaction force at: (a) the front axle and (b) the rear axle of the Thalys HST for a train speed of $218 \mathrm{~km} / \mathrm{h}$.

frequency range between 50 and $100 \mathrm{~Hz}$ where the train-track resonance occurs, however, the effect of the train speed on the track compliance is small (Fig. 12). The frequency content of the axle loads in this frequency range therefore mainly depends on the train speed $v$ through the frequency content of the track unevenness. As the PSD $\hat{S}_{w / r}(\omega)$ increases proportional to $v^{2.5}$, the generated track unevenness $\hat{\mathbf{u}}_{w / r}$ increases with the train speed proportional to $v^{1.25}$. A decrease of the train speed from 294 to $218 \mathrm{~km} / \mathrm{h}$ results in a decrease of $69 \%$ of the frequency content of the axle loads, as observed in Figs. 14 and 15.

\subsection{Validation of the free field response}

The frequency content of the train-track interaction forces is used to compute the vibrations in the free field during the passage of a Thalys HST at train speeds of 294 and $218 \mathrm{~km} / \mathrm{h}$.

As for the calculation of the track compliance, the results for the transfer functions between the track and the free field are based on a solution of the equations of motion (8) of the coupled track-soil system with a force vector $\tilde{\mathbf{f}}_{\mathrm{tr}}$ equal to $\{0.5,0.5,0,0,0,0\}^{\mathrm{T}}$.

The frequency content of the free field response is calculated by means of Eq. (16). Fig. 16 compares the experimental and computed frequency content of the vertical free field velocity at $8,16,24,32,48$, and $64 \mathrm{~m}$ from the track. Both the experimental and computed results show how the frequency content is mainly situated in a range upto $100 \mathrm{~Hz}$, with a shift towards the lower frequencies for an increasing distance from the track.

As indicated in the discussion on the track model, the assumption of a continuous track excludes the parametric excitation due to the discrete support of the rails by the sleepers. The passage on the sleepers excites the coupled track-train system at multiples of the sleeper passage frequency $f_{\mathrm{sl}}=v / d$, which is equal to $136 \mathrm{~Hz}$ for a train speed $v$ of $81.7 \mathrm{~m} / \mathrm{s}$ and a sleeper distance $d$ of $0.6 \mathrm{~m}$. Due to the Doppler effect, the first 


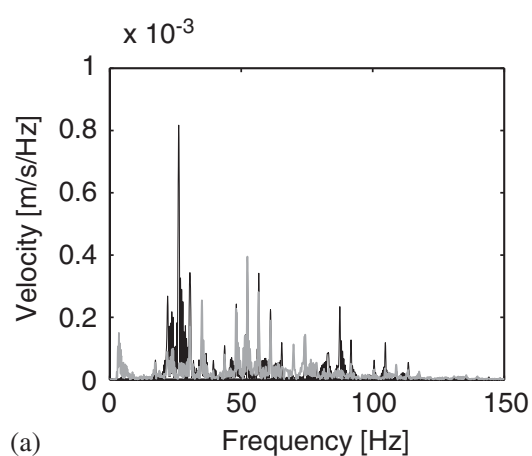

(a)

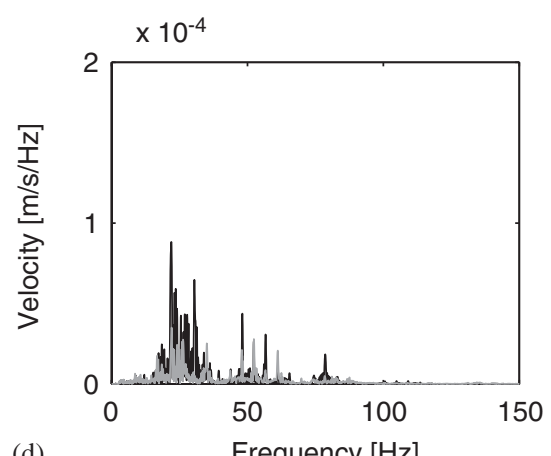

(d)
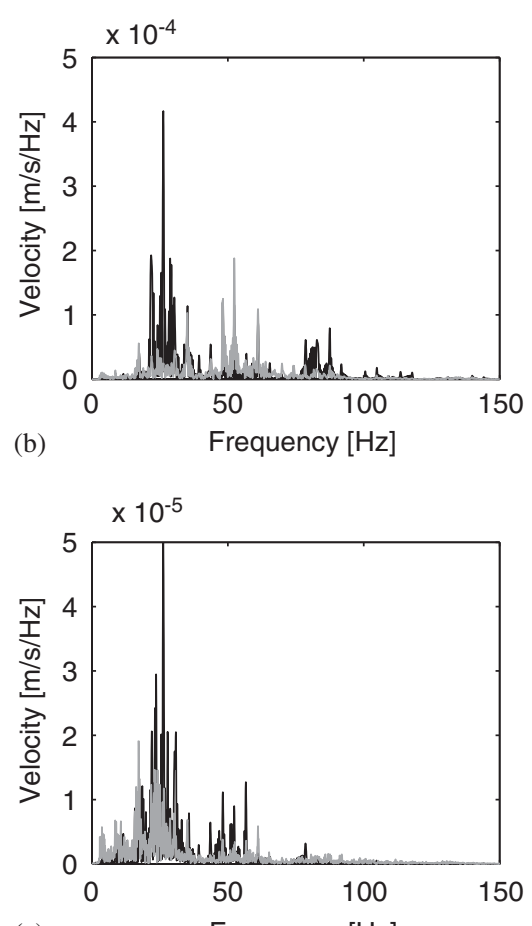

(e)
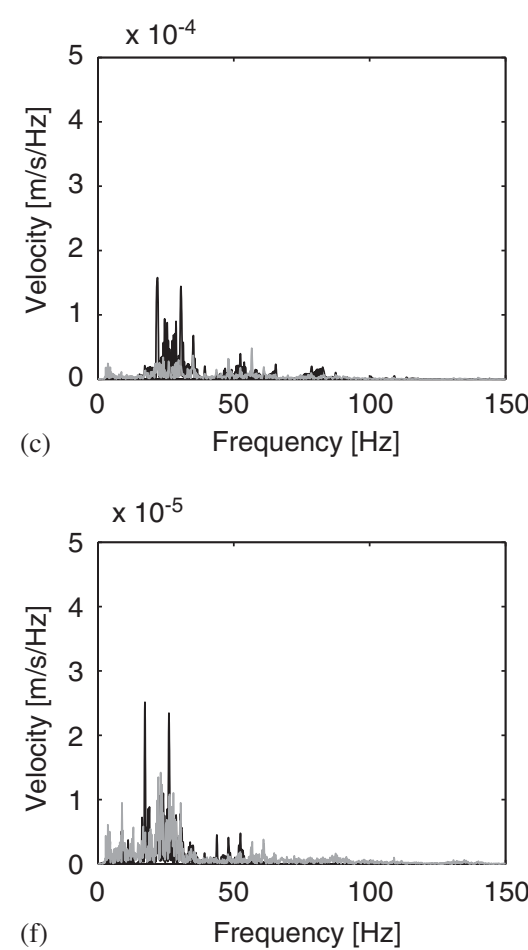

Fig. 16. The experimental (grey line) and computed (black line) frequency content of the vertical free field vibrations at a distance of: (a) $8 \mathrm{~m}$; (b) $16 \mathrm{~m}$; (c) $24 \mathrm{~m}$; (d) $32 \mathrm{~m}$; (e) $48 \mathrm{~m}$; and (f) $64 \mathrm{~m}$ from the track during the passage of the Thalys HST at a speed $v$ of $294 \mathrm{~km} / \mathrm{h}$.

harmonic of the resulting axle load contributes to the response in a fixed point in the free field in a frequency range between $f_{\mathrm{sl}} /(1+v / C)$ and $f_{\mathrm{sl}} /(1-v / C)$. For a Rayleigh wave velocity of $140 \mathrm{~m} / \mathrm{s}$, as obtained with the soil characteristics of the top layer, this corresponds to a frequency range between 86 and $327 \mathrm{~Hz}$. The sleeper passage effect is not clearly observable in the measured free field velocities, however.

A clearer comparison of the experimental and computed frequency content is obtained by the one-third octave band RMS spectra (Fig. 17) of the response. These spectra are computed according to the German standard DIN 45672-2 [45] on a reference period $T_{2}$, during which the response is considered to be stationary. Superimposed on the one-third octave band spectra are the vibration criterion curves for sensitive equipment, that are given here as a reference only. At small distances from the track, an underestimation at low frequencies is observed due to the neglection of the quasi-static contribution to the free field response. Furthermore, the frequency content is overestimated between 20 and $40 \mathrm{~Hz}$ more severely than the track-free field transfer functions in Fig. 7. At higher frequencies, a better agreement is obtained, with a slight overestimation of the measured response. At larger distances of 32,48, and $64 \mathrm{~m}$ from the track, the overestimation diminishes and a good agreement between the experimental and computed results is observed, as for the track-free field transfer functions in Fig. 7.

Fig. 18 shows the time history of the free field velocity at a train speed of $294 \mathrm{~km} / \mathrm{h}$. At 8 and $16 \mathrm{~m}$ from the track, the passage of individual bogies can be identified. This is no longer the case at larger distances from the track. In both the experimental and computed results, the duration of the response increases in a similar way. When the amplitude of the experimental and computed free field vibrations are compared, the previous observations are confirmed: at small distances from the track, the response is overestimated, while at larger distances a better agreement is obtained.

Fig. 19 shows the frequency content of the vertical free field velocity at a train speed of $218 \mathrm{~km} / \mathrm{h}$. Compared to the results at the higher train speed of $294 \mathrm{~km} / \mathrm{h}$ (Fig. 16), the frequency content at low frequencies is much lower. In the frequency range between 50 and $100 \mathrm{~Hz}$, where the train-track interaction occurs, a similar reduction is observed as for the frequency content of the train-track interaction forces (Figs. 14 and 15). In the 

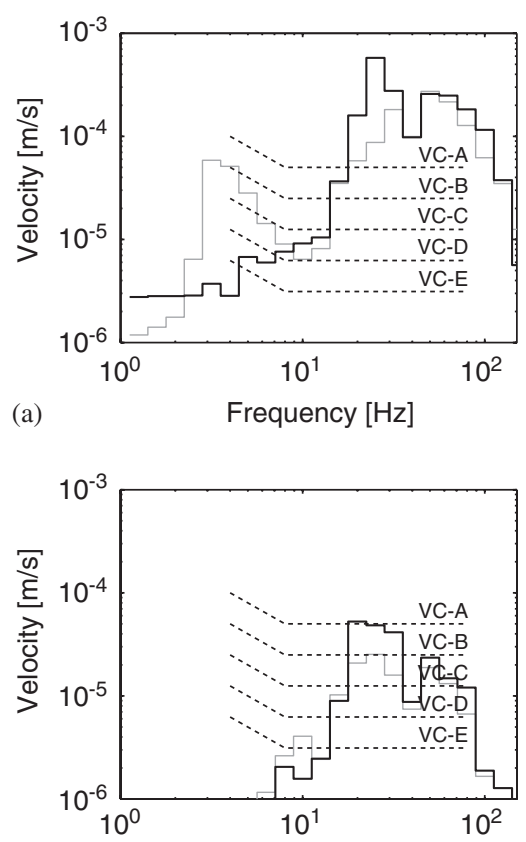

(d)

Frequency $[\mathrm{Hz}]$
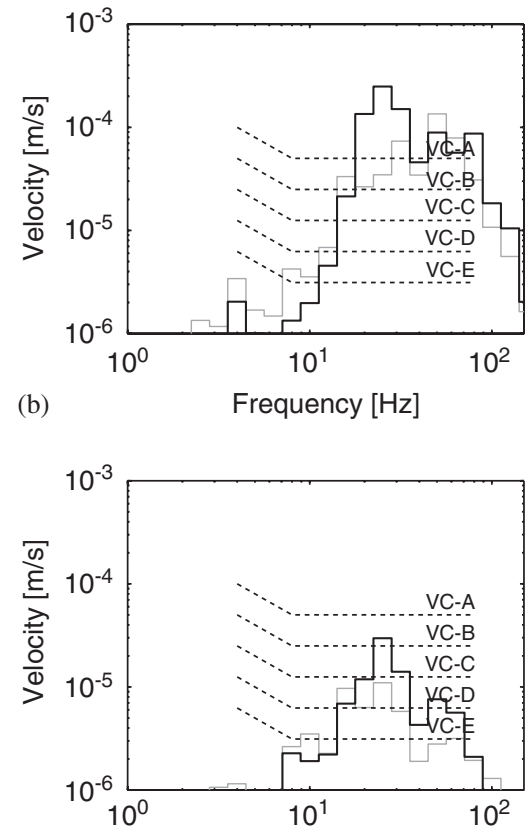

(e)

Frequency [Hz]
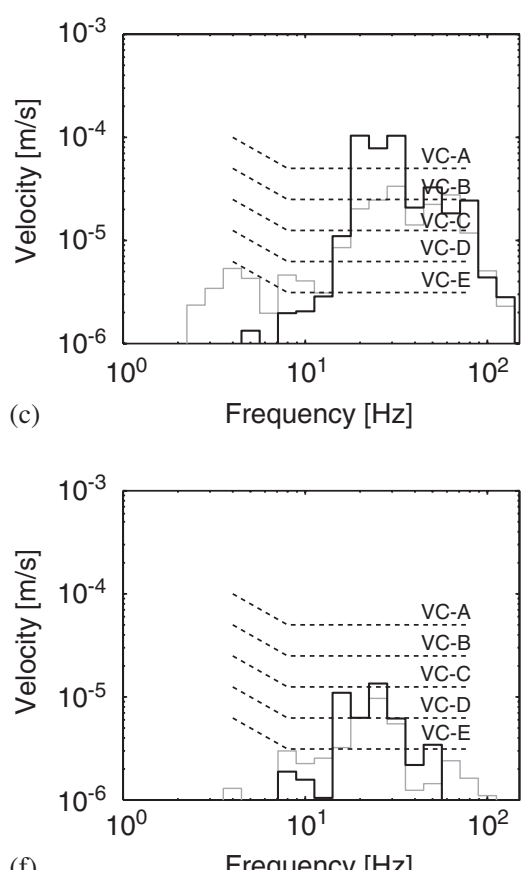

(f)

Fig. 17. The experimental (grey line) and computed (black line) one-third octave band RMS spectra of the vertical free field vibrations at a distance of: (a) $8 \mathrm{~m}$, (b) $16 \mathrm{~m}$, (c) $24 \mathrm{~m}$, (d) $32 \mathrm{~m}$, (e) $48 \mathrm{~m}$, and (f) $64 \mathrm{~m}$ from the track during the passage of the Thalys HST at a speed $v$ of $294 \mathrm{~km} / \mathrm{h}$.

experimental results, a small contribution of the sleeper passage effect is observed around the sleeper passage frequency $f_{\mathrm{sl}}=101 \mathrm{~Hz}$.

Fig. 20 compares the one-third octave band RMS spectra of the computed and measured response at a train speed of $218 \mathrm{~km} / \mathrm{h}$. A satisfactory agreement is obtained, with an overestimation of the measured response in the frequency range between 20 and $40 \mathrm{~Hz}$.

Fig. 21 shows the time history of the vertical free field velocity at a train speed of $218 \mathrm{~km} / \mathrm{h}$. At small distances from the track, both the experimental and the computed results show a lower vibration level for this lower train speed. This effect is less pronounced for larger distances from the track.

\section{Conclusion}

In this paper, the experimental validation of a numerical model for the prediction of railway induced vibrations has been presented. The model fully accounts for the dynamic interaction between the train, the track and the soil by means of a compliance formulation in the moving frame of reference. The results illustrate the importance of the coupling of the train and the track model in the frequency range of interest for traffic induced vibrations in buildings.

An elaborate measurement campaign has been performed to validate the numerical model. The measurement campaign consists of experiments that have been performed to identify model parameters and experiments that are used to validate the numerical model. A SASW test and a track receptance test have been used to determine the dynamic soil and track parameters. The transfer functions between a steel foundation and the free field and between the track and the free field have subsequently been used to validate the numerical model. The experimental and numerical track-free field transfer functions show a relatively good agreement, although at small distances an overestimation of the experimental response is observed. Finally, the sleeper response and the free field vibrations due to the passage of the Thalys HST have been predicted and 

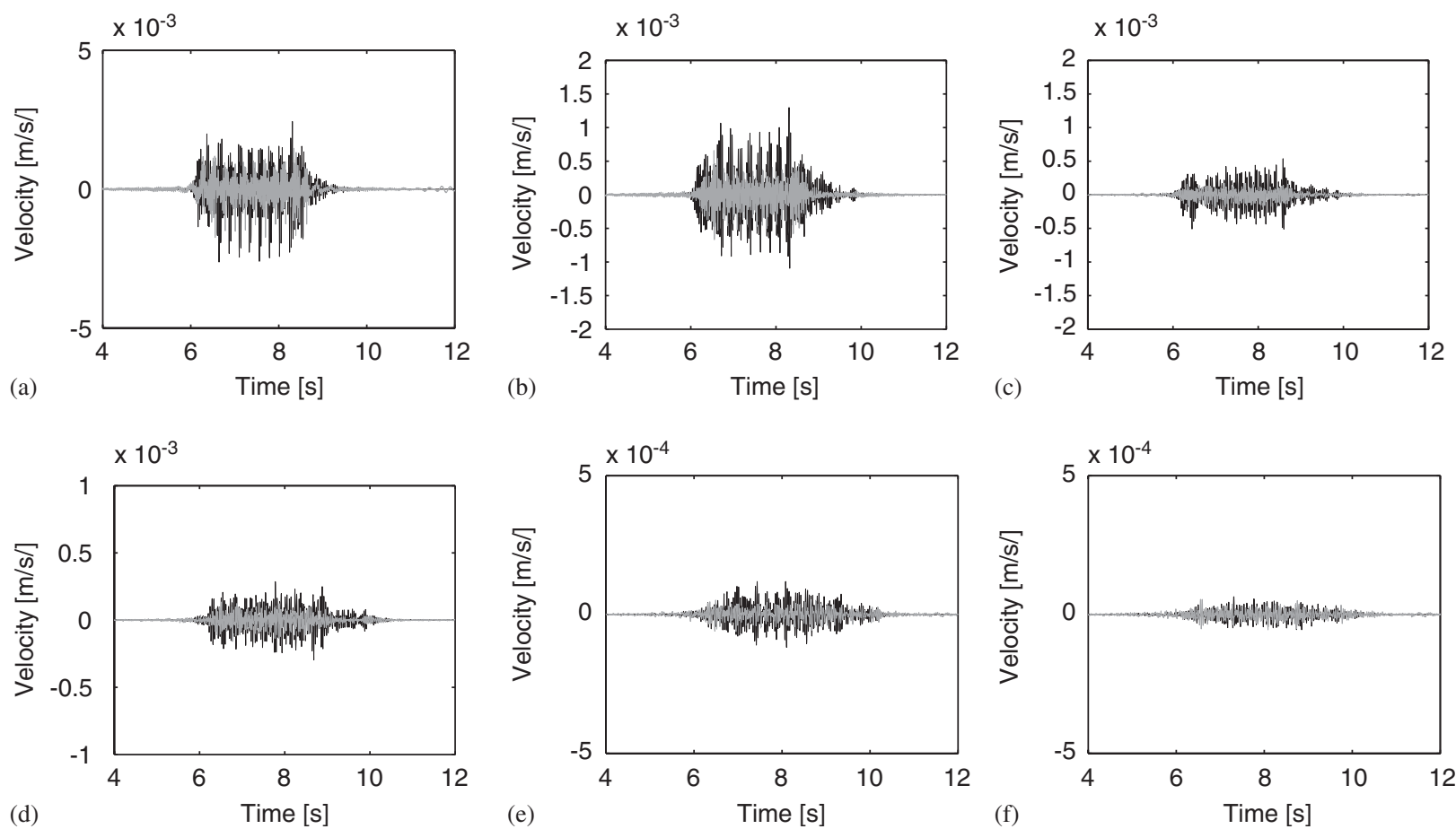

Fig. 18. The experimental (grey line) and computed (black line) time history of the vertical free field vibrations at a distance of: (a) $8 \mathrm{~m}$; (b) $16 \mathrm{~m}$; (c) $24 \mathrm{~m}$; (d) $32 \mathrm{~m}$; (e) $48 \mathrm{~m}$; and (f) $64 \mathrm{~m}$ from the track during the passage of the Thalys HST at a speed $v$ of $294 \mathrm{~km} / \mathrm{h}$.

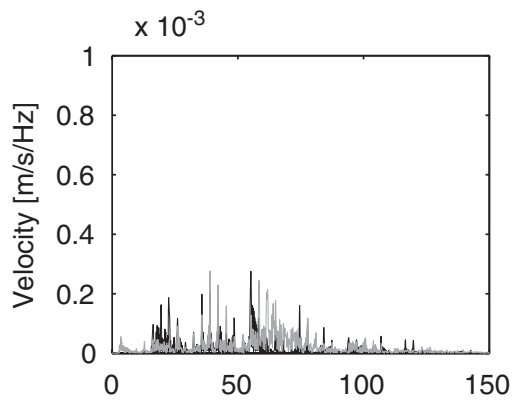

(a)

Frequency $[\mathrm{Hz}]$

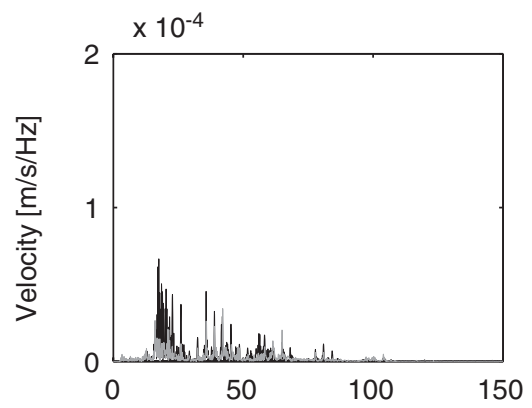

(d)

Frequency [Hz]

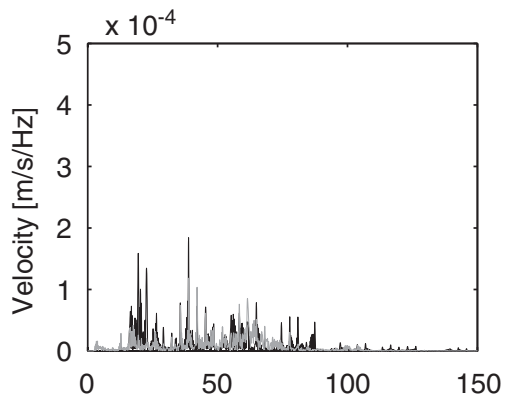

(b)

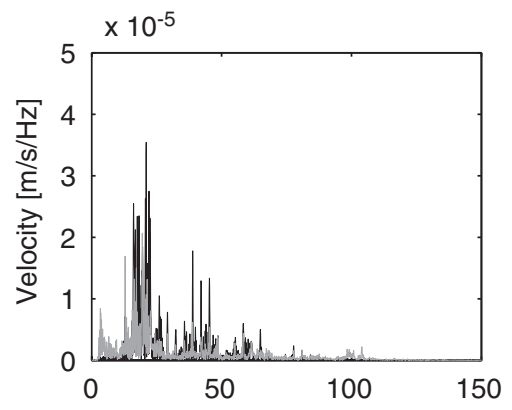

(e)

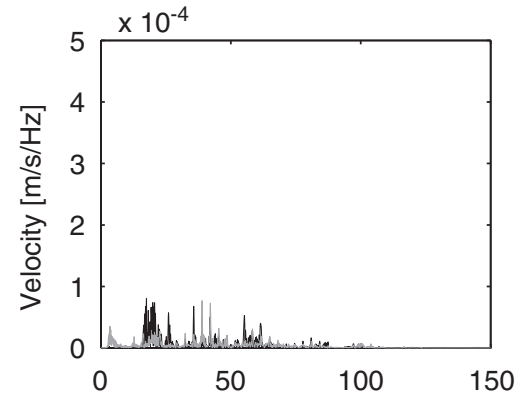

(c)

Frequency [Hz]

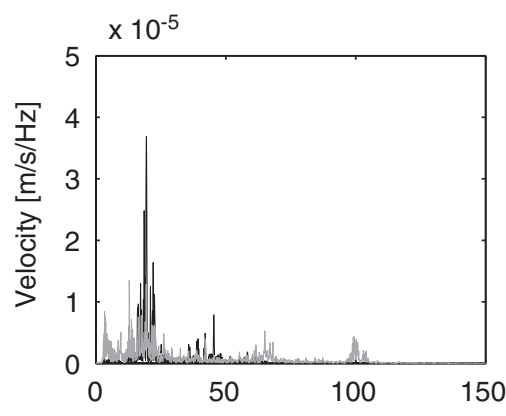

(f)

Frequency [Hz]

Fig. 19. The experimental (grey line) and computed (black line) frequency content of the vertical free field vibrations at a distance of: (a) $8 \mathrm{~m}$; (b) $16 \mathrm{~m}$; (c) $24 \mathrm{~m}$; (d) $32 \mathrm{~m}$; (e) $48 \mathrm{~m}$; and (f) $64 \mathrm{~m}$ from the track during the passage of the Thalys HST at a speed $v$ of $218 \mathrm{~km} / \mathrm{h}$. 


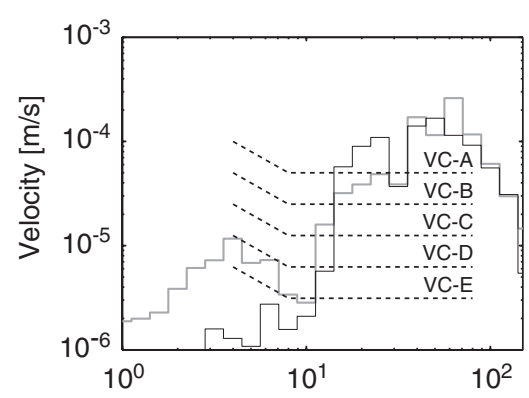

(a)

Frequency $[\mathrm{Hz}]$

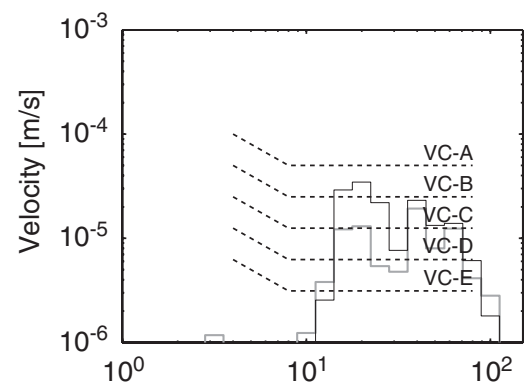

(d)

Frequency $[\mathrm{Hz}]$

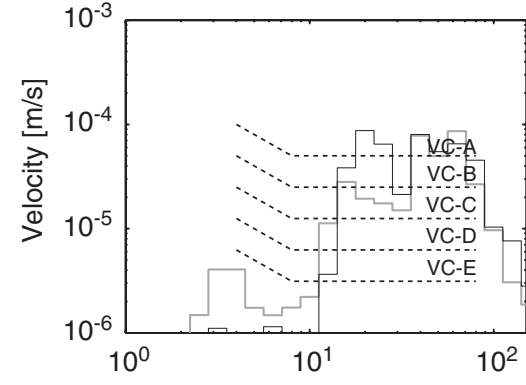

(b)

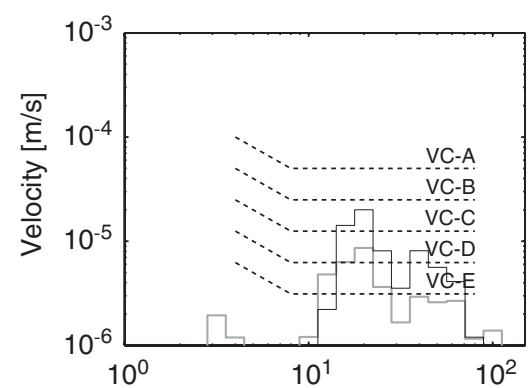

(e)
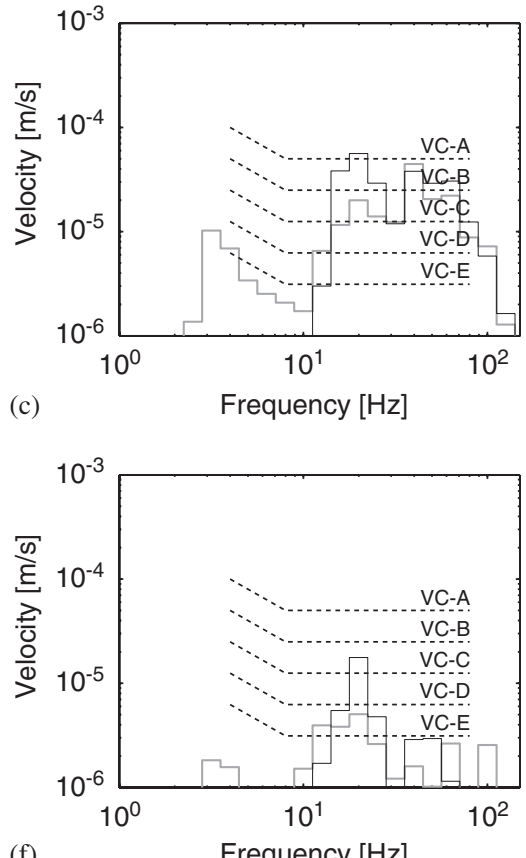

(f)

Frequency $[\mathrm{Hz}]$

Fig. 20. The experimental (grey line) and computed (black line) one-third octave band RMS spectra of the vertical free field vibrations at a distance of: (a) $8 \mathrm{~m}$; (b) $16 \mathrm{~m}$; (c) $24 \mathrm{~m}$; (d) $32 \mathrm{~m}$; (e) $48 \mathrm{~m}$; and (f) $64 \mathrm{~m}$ from the track during the passage of the Thalys HST at a speed $v$ of $218 \mathrm{~km} / \mathrm{h}$.

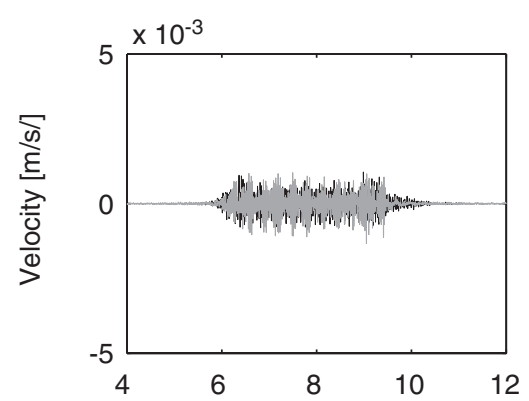

(a)

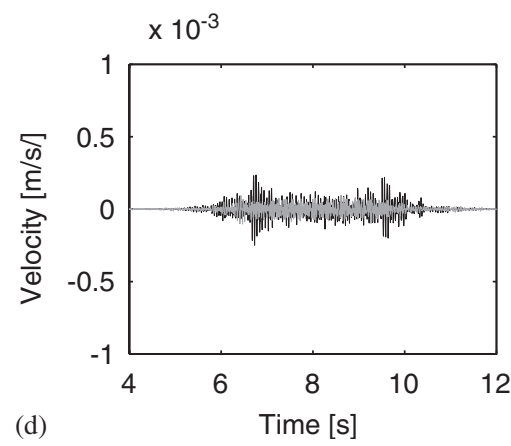

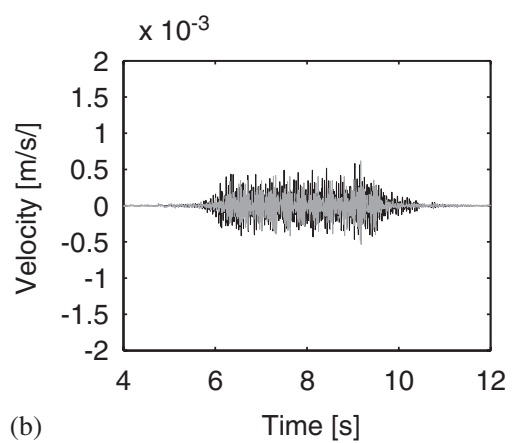
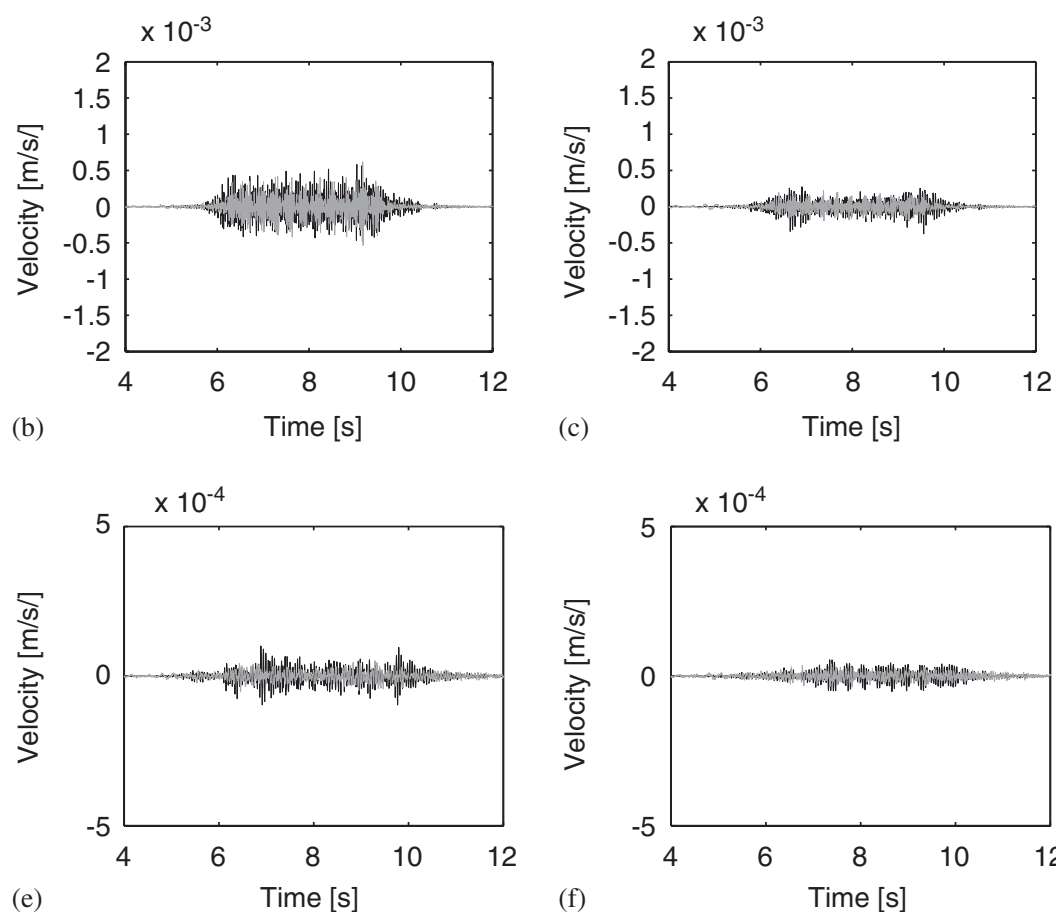

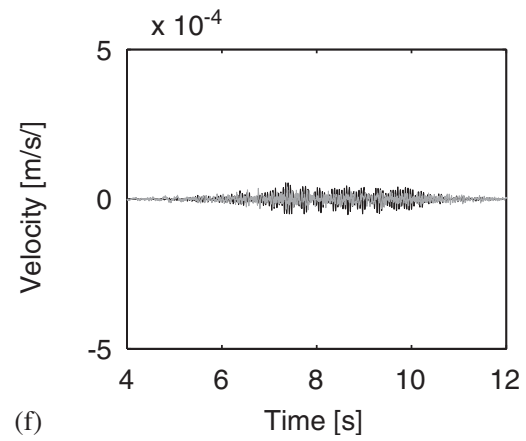

Fig. 21. The experimental (grey line) and computed (black line) time history of the vertical free field vibrations at a distance of: (a) $8 \mathrm{~m}$; (b) $16 \mathrm{~m}$; (c) $24 \mathrm{~m}$; (d) $32 \mathrm{~m}$; (e) $48 \mathrm{~m}$; and (f) $64 \mathrm{~m}$ from the track during the passage of the Thalys HST at a speed $v$ of $218 \mathrm{~km} / \mathrm{h}$. 
validated for two train speeds. The step-wise validation allows to understand how errors propagate in the prediction model. The results emphasize the crucial role of the dynamic soil properties.

Given the large number of modelling uncertainties, the numerical results of the free field vibrations show a good agreement with the experimental results. Additional measurement campaigns, where more attention goes to the train-track interaction, seem desirable in order to further validate and confirm the applicability of numerical models for the prediction of railway induced vibrations.

\section{Acknowledgements}

The results presented in this paper have been obtained within the frame of the STWW project IWT 000152 "Traffic induced vibrations in buildings". The financial support of the Flemish Community is kindly acknowledged.

\section{References}

[1] S.N. Veritchev, Instability of a vehicle moving on an elastic structure, PhD Thesis, TU Delft, 2002.

[2] K. Adolfsson, B. Andréasson, P.-E. Bengtson, A. Bodare, C. Madshus, R. Massarch, G. Wallmark, P. Zackrisson, High speed lines on soft ground. Evaluation and analyses of measurements from the West Coast Line, Technical Report, Banverket, Sweden, 1999.

[3] A.M. Kaynia, C. Madshus, P. Zackrisson, Ground vibration from high speed trains: prediction and countermeasure, Journal of Geotechnical and Geoenvironmental Engineering, Proceedings of the ASCE 126 (6) (2000) 531-537.

[4] C. Madshus, A.M. Kaynia, High-speed railway lines on soft ground: dynamic behaviour at critical train speed, Journal of Sound and Vibration 231 (3) (2000) 689-701.

[5] T. Ekevid, N.-E. Wiberg, Wave propagation related to high-speed train. A scaled boundary FE-approach for unbounded domains, Computer Methods in Applied Mechanics and Engineering 191 (2002) 3947-3964.

[6] L. Andersen, S.R.K. Nielsen, Boundary element analysis of the steady-state response of an elastic half-space to a moving force on its surface, Engineering Analysis with Boundary Elements 27 (2003) 23-38.

[7] M. Heckl, G. Hauck, R. Wettschureck, Structure-borne sound and vibration from rail traffic, Journal of Sound and Vibration 193 (1) (1996) 175-184.

[8] H.E.M. Hunt, Modelling of rail vehicles and track for calculation of ground vibration transmission into buildings, Journal of Sound and Vibration 193 (1) (1996) 185-194.

[9] X. Sheng, C.J.C. Jones, M. Petyt, Ground vibration generated by a harmonic load acting on a railway track, Journal of Sound and Vibration 225 (1) (1999) 3-28.

[10] X. Sheng, C.J.C. Jones, M. Petyt, Ground vibration generated by a load moving along a railway track, Journal of Sound and Vibration 228 (1) (1999) 129-156.

[11] X. Sheng, C.J.C. Jones, D.J. Thompson, A comparison of a theoretical model for quasi-statically and dynamically induced environmental vibration from trains with measurements, Journal of Sound and Vibration 267 (3) (2003) 621-635.

[12] X. Sheng, C.J.C. Jones, D.J. Thompson, A theoretical model for ground vibration from trains generated by vertical track irregularities, Journal of Sound and Vibration 272 (3-5) (2004) 937-965.

[13] L. Auersch, The excitation of ground vibration by rail traffic: theory of vehicle-track-soil interaction and measurements on highspeed lines, Journal of Sound and Vibration 284 (1-2) (2005) 103-132.

[14] A.V. Metrikine, S.N. Verichev, J. Blauwendraad, Stability of a two-mass oscillator moving on a beam supported by a visco-elastic half-space, International Journal of Solids and Structures 42 (2005) 1187-1207.

[15] A.V. Metrikine, K. Popp, Steady-state vibrations of an elastic beam on a visco-elastic layer under moving load, Archive of Applied Mechanics 70 (2000) 399-408.

[16] S. François, Trillingen ten gevolge van de Thalys hogesnelheidstrein op de lijn L2 Brussel-Keulen: in situ metingen en numerieke voorspellingen, Master's Thesis, Department of Civil Engineering, K.U. Leuven, 2003.

[17] G. Lombaert, S. François, G. Degrande, J. Kogut, Validation of a numerical model for railway induced vibrations, Proceedings of the sixth National Congress on Theoretical and Applied Mechanics, Ghent, Belgium, National Committee for Theoretical and Applied Mechanics, May 2003.

[18] G. Lombaert, G. Degrande, D. Clouteau, Numerical modelling of free field traffic induced vibrations, Soil Dynamics and Earthquake Engineering 19 (7) (2000) 473-488.

[19] G. Lombaert, Development and Experimental Validation of a Numerical Model for the Free Field Vibrations Induced by Road Traffic, PhD Thesis, Department of Civil Engineering, K.U. Leuven, 2001.

[20] G. Lombaert, G. Degrande, Experimental validation of a numerical prediction model for free field traffic induced vibrations by in situ experiments, Soil Dynamics and Earthquake Engineering 21 (6) (2001) 485-497.

[21] G. Lombaert, G. Degrande, The experimental validation of a numerical model for the prediction of the vibrations in the free field produced by road traffic, Journal of Sound and Vibration 262 (2003) 309-331.

[22] D. Clouteau, G. Degrande, G. Lombaert, Numerical modelling of traffic induced vibrations, Meccanica 36 (4) (2001) 401-420. 
[23] S. Nazarian, M.R. Desai, Automated surface wave method: field testing, Journal of Geotechnical Engineering, Proceedings of the ASCE 119 (7) (1993) 1094-1111.

[24] D. Yuan, S. Nazarian, Automated surface wave method: inversion technique, Journal of Geotechnical Engineering, Proceedings of the ASCE 119 (7) (1993) 1112-1126.

[25] L. Pyl, G. Degrande, Determination of the dynamic soil characteristics with the SASW method at a site in Lincent, Report BWM2001-02, Department of Civil Engineering, K.U.Leuven, STWW Programme Technology and Economy, Project IWT-000152, August 2001.

[26] J. Kogut, G. Degrande, Transfer functions between the HST track and the free field on the line L2 Brussels-Köln in Lincent. Report BWM-2003-03, Department of Civil Engineering, K.U.Leuven, January 2003, STWW Programme Technology and Economy, Project IWT-000152.

[27] J. Kogut, G. Degrande, Free field vibrations due to the passage of an IC train and a Thalys high speed train on the L2 track Brussels-Köln, Report BWM-2002-10, Department of Civil Engineering, K.U. Leuven, STWW Programme Technology and Economy, Project IWT-000152, November 2002.

[28] J. Kogut, G. Degrande, W. Haegeman, Free field vibrations due to the passage of an IC train and a Thalys HST on the high speed track L2 Brussels-Köln. Proceedings of the Sixth National Congress on Theoretical and Applied Mechanics, Ghent, Belgium, National Committee for Theoretical and Applied Mechanics, May 2003.

[29] K. Knothe, S.L. Grassie, Modelling of railway track and vehicle/track interaction at high frequencies, Vehicle Systems Dynamics 22 (1993) 209-262.

[30] K. Knothe, Y. Wu, Receptance behaviour of railway track and sub-grade, Archive of Applied Mechanics 68 (1998) 457-470.

[31] G. Lombaert, G. Degrande, The isolation of railway induced vibrations by means of resilient track elements, in: C. Soize (Ed.), Proceedings of the sixth European Conference on Structural Dynamics: Eurodyn 2005, Paris, France, September 2005.

[32] D. Aubry, D. Clouteau, G. Bonnet, Modelling of wave propagation due to fixed or mobile dynamic sources, in: N. Chouw, G. Schmid (Eds.), Workshop Wave '94, Wave propagation and Reduction of Vibrations, Ruhr Universität Bochum, Germany, December 1994, pp. 109-121.

[33] J.E. Luco, R.J. Apsel, On the Green's functions for a layered half-space. Part I, Bulletin of the Seismological Society of America 4 (1983) 909-929.

[34] F.C.P. de Barros, J.E. Luco, Moving Green's functions for a layered visco-elastic halfspace, Technical Report, Department of Applied Mechanics and Engineering Sciences, University of California, San Diego, La Jolla, California, May 1992.

[35] E. Kausel, J.M. Roësset, Stiffness matrices for layered soils, Bulletin of the Seismological Society of America 71 (6) (1981) $1743-1761$.

[36] W. Haegeman, In situ tests Retie-Waremme-Lincent, Report RUG IV.1.16.3, Soil Mechanics Laboratory, Ghent University, STWW Programme Technology and Economy, Project IWT-000152, September 2001.

[37] D. Clouteau, Propagation d'ondes Dans des Milieux Hétérogènes. Application à La Tenue Des Ouvrages Sous Séismes, PhD Thesis, Laboratoire de Mécanique des Sols, Structures et Matériaux, Ecole Centrale de Paris, 1990.

[38] D. Aubry, D. Clouteau, A subdomain approach to dynamic soil-structure interaction, in: V. Davidovici, R.W. Clough (Eds.), Recent advances in Earthquake Engineering and Structural Dynamics, Ouest Editions/AFPS, Nantes, 1992, pp. 251-272

[39] L. Auersch, Wave propagation in layered soils: theoretical solution in wavenumber domain and experimental results of hammer and railway traffic excitation, Journal of Sound and Vibration 173 (2) (1994) 233-264.

[40] G. Degrande, G. Lombaert, An efficient formulation of Krylov's prediction model for train induced vibrations based on the dynamic reciprocity theorem, Journal of the Acoustical Society of America 110 (3) (2001) 1379-1390.

[41] R. Van Leeuwen, Meetautorail EM130 documentatie, Technical Report, NMBS, 2002.

[42] C. Esveld, Modern railway track, MRT-Productions, Zaltbommel, 2001.

[43] H. Braun, T. Hellenbroich, Messergebnisse von Strassenunebenheiten, VDI Berichte 877 (1991) 47-80.

[44] D.E. Newland, An Introduction to Random Vibrations, Spectral \& Wavelet Analysis, Longman Scientific \& Technical, Essex, England, 1994.

[45] Deutsches Institut für Normung, DIN 45672 Teil 2: Schwingungsmessungen in der Umgebung von Schienenverkehrswegen: Auswerteverfahren, 1995. 